\title{
Fibroblasts induce expression of FGF4 in ovarian cancer stem-like cells/cancer-initiating cells and upregulate their tumor initiation capacity
}

\author{
Kazuyo Yasuda', Toshihiko Torigoe ${ }^{1}$, Tasuku Mariya ${ }^{1,2}$, Takuya Asano ${ }^{1,2}$, Takafumi Kuroda², Junichi Matsuzaki ${ }^{1}$ \\ Kanae Ikeda ${ }^{3}$, Makoto Yamauchi ${ }^{3}$, Makoto Emori ${ }^{1}$, Hiroko Asanuma ${ }^{4}$, Tadashi Hasegawa ${ }^{4}$, Tsuyoshi Saito ${ }^{2}$, \\ Yoshihiko Hirohashi ${ }^{1}$ and Noriyuki Sato ${ }^{1}$
}

Cancer stem-like cells (CSCs)/cancer-initiating cells (CICs) are defined as a small population of cells within cancer that contribute to cancer initiation and progression. Cancer-associated fibroblasts (CAFs) are stromal fibroblasts surrounding tumor cells, and they have important roles in tumor growth and tumor progression. It has been suggested that stromal fibroblasts and CSCs/CICs might mutually cooperate to enhance their growth and tumorigenic capacity. In this study, we investigated the effects of fibroblasts on tumor-initiating capacity and stem-like properties of ovarian CSCs/CICs. CSCs/ $\mathrm{CICs}$ were isolated from the ovarian carcinoma cell line HTBoA as aldehyde dehydrogenase 1 high $\left(\mathrm{ALDH} 1^{\text {high }}\right)$ population by the ALDEFLUOR assay. Histological examination of tumor tissues derived from ALDH $1{ }^{\text {high }}$ cells revealed few fibrous stroma, whereas those derived from fibroblast-mixed ALDH $1^{\text {high }}$ cells showed abundant fibrous stroma formation. In vivo tumor-initiating capacity and in vitro sphere-forming capacity of $A L D H 1$ high cells were enhanced in the presence of fibroblasts. Gene expression analysis revealed that fibroblast-mixed ALDH 1 high cells had enhanced expression of fibroblast growth factor 4 (FGF4) as well as stemness-associated genes such as SOX2 and POU5F1. Sphere-forming capacity of $\mathrm{ALDH} 1^{\text {high }}$ cells was suppressed by small-interfering RNA (siRNA)-mediated knockdown of FGFR2, the receptor for FGF4 which was expressed preferentially in $\mathrm{ALDH} 1^{\text {high }}$ cells. Taken together, the results indicate that interaction of fibroblasts with ovarian $\mathrm{CSCs} / \mathrm{CICs}$ enhanced tumor-initiating capacity and stem-like properties through autocrine and paracrine FGF4-FGFR2 signaling.

Laboratory Investigation (2014) 94, 1355-1369; doi:10.1038/labinvest.2014.122; published online 20 October 2014

Tumors are composed of morphologically and phenotypically heterogeneous cells that are derived from a small subpopulation of pluripotent stem-like cancer cells (cancer stem cell hypothesis). ${ }^{1-3}$ Cancer stem-like cells (CSCs) are also named as cancer-initiating cells (CICs) since they possess high tumorigenic capacity in vivo. With recent progress in this research field, CSCs/CICs have been isolated by several methods. ${ }^{4}$ CSCs/CICs are now defined as a small population of cancer cells that have (1) high tumor-initiating capacity, (2) self-renewal capacity and (3) differentiation potential. Since CSCs/CICs are resistant to conventional cancer therapies including chemotherapy, radiotherapy and some molecular targeting therapies, they are thought to be responsible for disease recurrence and distant metastasis. ${ }^{5}$ CSCs/CICs have phenotypic properties similar to those of normal stem cells; however, the molecular mechanisms underlying their high tumorigenic capacity, a hallmark of CSCs/CICs, are still elusive.

Tumor microenvironments have important roles in cancer progression. ${ }^{6}$ They are composed of cancer cells and surrounding stromal elements, such as blood vessels, inflammatory cells and fibroblasts, which are termed as cancer-associated fibroblasts (CAFs). ${ }^{7}$ CAFs are activated fibroblasts that can be identified by immunohistochemical staining using anti- $\alpha$ smooth muscle actin $(\alpha$-SMA $){ }^{8,9}$ These fibroblasts are also known as reactive fibroblasts, peri-tumor fibroblasts and

\footnotetext{
${ }^{1}$ Department of Pathology, Sapporo Medical University School of Medicine, Sapporo, Japan; ${ }^{2}$ Department of Obstetrics and Gynecology, Sapporo Medical University School of Medicine, Sapporo, Japan; ${ }^{3}$ Department of Plastic and Reconstructive Surgery, Sapporo Medical University School of Medicine, Sapporo, Japan and ${ }^{4}$ Department of Surgical Pathology, Sapporo Medical University School of Medicine, Sapporo, Japan

Correspondence: Dr K Yasuda, MD, PhD or Dr T Torigoe, MD, PhD or Dr Y Hirohashi, MD, PhD, Department of Pathology, Sapporo Medical University School of Medicine, South-1 West-17, Chuo-Ku, Sapporo 060-8556, Japan.

E-mail: yasudasann@gmail.com, torigoe@sapmed.ac.jp or hirohash@sapmed.ac.jp

Received 25 February 2014; revised 5 August 2014; accepted 18 August 2014
} 
myofibroblasts. ${ }^{10}$ CAFs are observed in various types of malignancies including gastric cancer, ovarian cancer and breast cancer. In many cases, tumors with abundant CAFs have a poorer prognosis than those of tumors with less CAFs, since CAFs have significant roles in the tumor microenvironment for promotion of cell growth and invasion. ${ }^{11,12}$ It has also been suggested that CSCs/CICs might preferentially interact with CAFs, which serve as a niche in the CSC/CIC microenvironment. ${ }^{13}$

In this study, we show evidence that fibroblasts can induce expression of stemness-associated genes and fibroblast growth factor 4 (FGF4) in ovarian carcinoma CSCs/CICs, leading enhancement of tumor-initiating capacity. Our study highlights the significance of FGF4-FGFR2 signaling induced by the interaction between fibroblasts and CSCs/CICs in the tumor microenvironment.

\section{MATERIALS AND METHODS Cell Culture}

The experiments were conducted with the approval of the Sapporo Medical University Study Review Board. The human ovarian carcinoma cell line HTBoA was previously established from an ovarian anaplastic carcinoma. ${ }^{14}$ Human primary skin fibroblasts $\mathrm{N} 25-5$ and N30-3 were prepared from normal skin tissues of two Japanese patients who underwent plastic surgery after obtaining informed consent, in compliance with the ethical guidelines of Sapporo Medical University School of Medicine. All cells were maintained in Dulbecco's modified Eagle's medium (DMEM; SigmaAldrich, St Louis, MO, USA) supplemented with 10\% FBS in a $5 \% \mathrm{CO}_{2}$ incubator at $37^{\circ} \mathrm{C}$.

\section{ALDEFLUOR Assay}

An ALDEFLUOR assay kit was purchased from Stem Cell Technologies (Vancouver, BC, Canada) and used according to the manufacturer's recommendations. Briefly, $10^{6}$ cells were suspended in $1 \mathrm{ml}$ assay buffer containing $1.5 \mathrm{mM}$ of an ALDH1 substrate, BODIPY ${ }^{\circledR}$-aminoacetaldehyde (BAAA), and incubated for $50 \mathrm{~min}$ at $37^{\circ} \mathrm{C}$. An inhibitor of ALDH1, diethylamino-benzaldehyde (DEAB), at a 10-fold molar excess was used as a negative control. Flow cytometry and cell sorting were performed using a FACS Aria II cell sorter (BD Biosciences, Bedford, MA, USA).

\section{In Vivo Tumor Formation Assay}

The experiments were conducted with the approval of the Sapporo Medical University Study Review Board. ALDH1 $1^{\text {high }}$ cells and ALDH1 ${ }^{\text {low }}$ cells isolated from HTBoA cells were resuspended at $10^{2}-10^{4}$ cells in $50 \mu \mathrm{l}$ of PBS and mixed with $50 \mu \mathrm{l}$ of matrigel (BD Biosciences). The cell-matrigel mixture suspension was subcutaneously injected in the dorsum of 6-week-old non-obese diabetic/severe combined immunodeficiency (NOD/SCID) mice (NOD.CB17-Prdkcscid/J, Charles River Laboratory, Yokohama, Japan) under anesthesia. Tumor growth was monitored weekly, and tumor volume was calculated by $X Y^{2} / 2$ ( $X=$ long axis, $Y=$ short axis). For a fibroblast mixture study, $10^{4}$ of ALDH1 $1^{\text {high }}$ cells or ALDH $11^{\text {low }}$ cells were mixed with $10^{4}$ of fibroblasts and suspended in $100 \mu \mathrm{l}$ of PBS matrigel mixture. Tumor growth was monitored weekly.

\section{Sphere Formation Assay}

ALDH $1^{\text {high }}$ cells and ALDH1 $1^{\text {low }}$ cells were isolated from HTBoA cells and incubated in CSC Certified ${ }^{\mathrm{TM}}$, Complete Serum-Free Medium (Cell Systems Corporation, Kirkland, WA, USA) using six-well ultra-low attachment plates (Corning, Corning, NY, USA). One thousand cells were seeded in each well, and the total number of spheres was counted 2 weeks after incubation. For a fibroblast mixture study, $10^{3}$ of fibroblasts were mixed with $10^{3}$ of ALDH1 $1^{\text {high }}$ cells or ALDH1 ${ }^{\text {low }}$ cells, and then the same sphere culture procedure was performed. Human recombinant FGF4 (Wako Pure Chemical Industries, Osaka, Japan) was added to the sphere formation assay culture medium to a final concentration of $0.2 \mathrm{ng} / \mathrm{ml}$. Fibroblast culture supernatant was obtained from fibroblast culture in CSC Certified ${ }^{\mathrm{TM}}$, Complete Serum-Free Medium after 2 days of culture. The supernatant was added to the sphere culture medium to a final concentration of $50 \%$.

\section{Immunohistochemical Staining}

Human leukocyte antigen (HLA) immunostaining was performed using mouse monoclonal anti-HLA class I antibody (clone: EMR8-5) as described previously. ${ }^{15}$ The monoclonal antibody was used at $1 \mu \mathrm{g} / \mathrm{ml} . \alpha$-SMA staining, FGF4 staining and FGFR2 staining were done using rabbit polyclonal antialpha smooth muscle actin antibody (Abcam, Cambridge, MA, USA), anti-FGF4 antibody (Abcam) and anti-FGFR2 antibody (Abcam). The antibodies were used at $1 \mu \mathrm{g} / \mathrm{ml}$.

\section{RT-PCR Analysis}

Total RNA was reverse-transcribed using Superscript II reverse transferase enzyme (Life Technologies, Grand Island, NY, USA). PCR was performed using Taq polymerase (Qiagen, Valencia, CA, USA). The thermal cycling conditions were $94{ }^{\circ} \mathrm{C}$ for $2 \mathrm{~min}$ followed by 35 cycles of $15 \mathrm{~s}$ at $94^{\circ} \mathrm{C}$, $30 \mathrm{~s}$ at $60^{\circ} \mathrm{C}$ and $30 \mathrm{~s}$ at $72^{\circ} \mathrm{C}$. Primer pairs used for RT-PCR analysis were $5^{\prime}$-TGTTAGCTGATGCCGACTTG- $3^{\prime}$ and $5^{\prime}$-TT CTTAGCCCGCTCAACACT- $3^{\prime}$ for ALDH1A1 with an expected PCR product size of 154 base pairs (bps), 5'-GCCTGGG CGCCGAGTGGA- $3^{\prime}$ and $5^{\prime}$-GGGCGAGCCGTTCATGTA GGTCTG- $3^{\prime}$ for SOX2 with an expected PCR product size of $301 \mathrm{bps}, 5^{\prime}$-AGGTGTTCAGCCAAACGACC- $3^{\prime}$ and $5^{\prime}$-TGAT CGTTTGCCCTTCTGGC-3' for POU5F1 (Oct3/4) with an expected PCR product size of $161 \mathrm{bps}, 5^{\prime}$-ATCCAGCTT GTCCCCAAAG- $3^{\prime}$ and $5^{\prime}$-ATTTCATTCGCTGGTTCTGG- ${ }^{\prime}$ for NANOG with an expected PCR product size of $459 \mathrm{bps}$, $5^{\prime}$-AGGCTGGGAGCCAAATGAAG- $3^{\prime}$ and $5^{\prime}$-TGTGGTC AAAAGCCCGTGG- $3^{\prime}$ for CD44 with an expected PCR product size of $83 \mathrm{bps}$, 5'-ATTTCATTGCTCCTGGGCG- ${ }^{\prime}$ 
and $5^{\prime}$-GCATACGTATTATAGCCCA-3' for FGF3 with an expected PCR product size of $642 \mathrm{bps}, 5^{\prime}$-TGAGTGCACGTT CAAGGAGA- $3^{\prime}$ and $5^{\prime}$-GAGGAAGTGGGTGACCTTCA- $3^{\prime}$ for FGF4 with an expected PCR product size of $154 \mathrm{bps}$, $5^{\prime}$-CCCGGATGGCAAAGTCAATGG- ${ }^{\prime}$ and $5^{\prime}$-TTCAGGGC AACATACCACTCCCG- $3^{\prime}$ for FGF5 with an expected PCR product size of $230 \mathrm{bps}, 5^{\prime}$-CACGAGGAGAACCCCTACA- $3^{\prime}$ and $5^{\prime}$-TCCCTTGGTACAAGTCTGA- $3^{\prime}$ for FGF6 with an expected PCR product size of $335 \mathrm{bps}, 5^{\prime}$-GTGGAAAAGAAC GGCAGTAAATACG-3' ${ }^{\prime}$ and 5'-CACCATACAGGCGATTAAG AAGACC-3' for FGFR2 with an expected PCR product size of $69 \mathrm{bps}, 5^{\prime}$-ATGAGCAACTGCAGCATCAC- $3^{\prime}$ and $5^{\prime}$-GGAG AAGCAGCATCTTCCAG-3' for TGFB1 with an expected PCR product size of $150 \mathrm{bps}$, 5'-CCCTGGCTACCTGAG TGAAG- $3^{\prime}$ and $5^{\prime}$-GGCTCGCAGTAGGTAACTGG- $3^{\prime}$ for SMAD2 with an expected PCR product size of $252 \mathrm{bps,}$ $5^{\prime}$-AACTCTTGGGACCTGGTGTG- ${ }^{\prime}$ and $5^{\prime}$-GTCCTTCTCC ACCCAAGTGA-3' for STAT3 with an expected PCR product size of $269 \mathrm{bps}$, $5^{\prime}$-GCTGAGGAAGATGCTGGTTC- $3^{\prime}$ and $5^{\prime}$-TCTTTCAACACGCAGGACAG- $3^{\prime}$ for $I L-1 B$ with an expected PCR product size of $248 \mathrm{bps}$, and $5^{\prime}$-ACCACAG TCCATGCCATCAC- $3^{\prime}$ and $5^{\prime}$-TCCACCACCCTGTTGCTG TA-3' for glyceraldehyde-3-phosphate dehydrogenase (GAPDH) with an expected product size of 452 bps. GAPDH was used as an internal control.

\section{Quantitative Real-Time PCR Analysis (qPCR)}

Quantitative real-time PCR was performed using the ABI PRISM 7000 Sequence Detection System (Applied Biosystems, Foster City, CA, USA) according to the manufacturer's protocol. ALDH1A1 (Hs00946916_m1), SOX2 (Hs01053049_s1), POU5F1 (Hs00999632_g1), NANOG (Hs04260366_g1), CD44 (Hs01075861_m1), DNAJB8 (Hs00542087_s1) primers and probes were designed by the manufacturer (TaqMan Gene expression assays; Applied Biosystems). Thermal cycling was performed using 40 cycles of $95^{\circ} \mathrm{C}$ for $15 \mathrm{~s}$ followed by $60^{\circ} \mathrm{C}$ for $1 \mathrm{~min}$. Each experiment was done in triplicate, and normalized to the GAPDH gene as an internal control.

\section{Gene Knockdown of FGFR2 with Small-Interfering RNA}

FGFR2 small-interfering RNAs (siRNAs) (SiHK0771) (Sigma, Tokyo, Japan) were used to knockdown FGFR2 mRNA. Transfection of siRNA duplexes was performed with Lipofectamine RNAimax (Life Technologies) according to the manufacturer's manual. Gene knockdown was confirmed by RT-PCR.

\section{Statistical Analysis}

Statistical analysis, data fitting and graphics were performed by the SPSS software package ver.19 (SPSS, Chicago, IL, USA). Data were shown as the mean \pm s.d. of at least three independent experiments and Student's $t$-test was used to assess the statistical significant difference $(P<0.05)$. Overall survival (OS), which was defined as interval from the date of first diagnosis to the date of death of disease progression, and progression-free survival (PFS), interval from the date of first diagnosis to the date of disease progression, were estimated using Kaplan-Meier method and compared with the log-rank test. The relevance with FGF4 expression was analyzed by Pearson's $\chi$-square tests. Correlation coefficient between
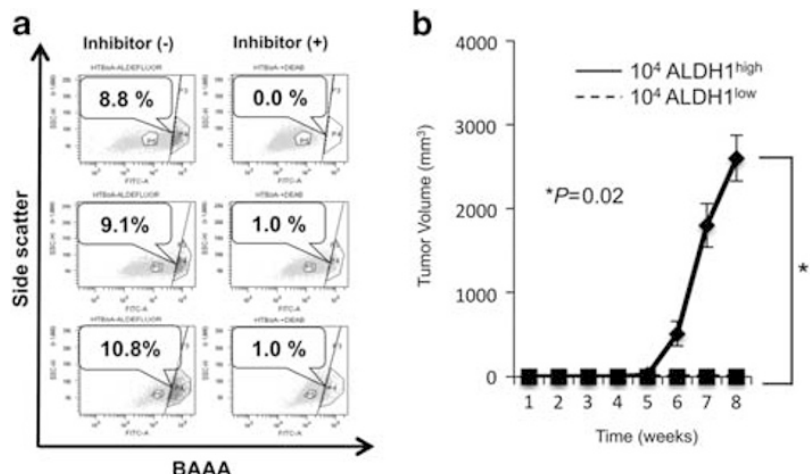

C

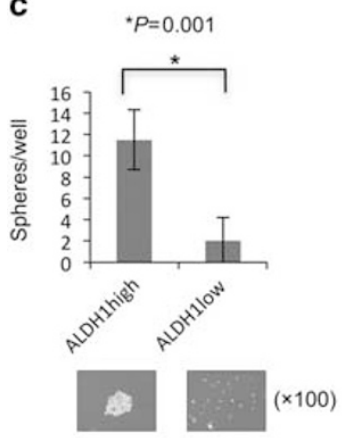

d
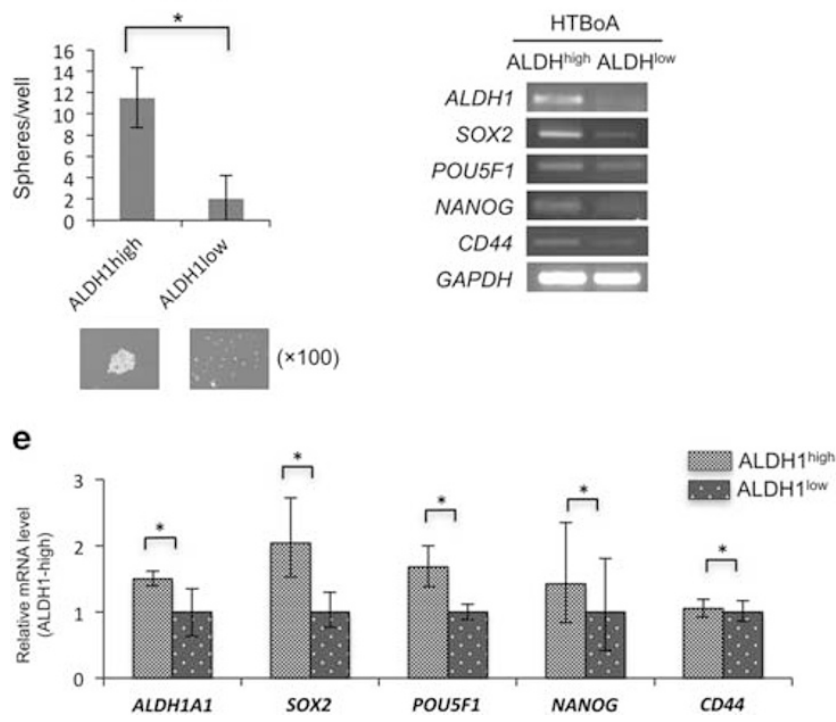

Figure $1 \mathrm{ALDH} 1^{\text {high }}$ cells of HTBoA have cancer stem-like properties. (a) Detection of ALDH $11^{\text {high }}$ cells by ALDEFLUOR assay. HTBoA ovarian adenocarcinoma cells were stained with BAAA and analyzed by a flow cytometer. The percentage represents the ratio of $A L D H^{\text {high }}$ cells. (b) Tumor formation assay of ALDH $1^{\text {high }}$ and $A L D H 1^{\text {low }}$ cells of HTBOA. $1 \times 10^{4} \mathrm{ALDH} 1^{\text {high }}$ cells and $1 \times 10^{4} \mathrm{ALDH} 1^{\text {low }}$ cells were inoculated subcutaneously into the backs of NOD/SCID mice. Tumor volume was measured weekly. Data represent means \pm s.d. Differences between $\mathrm{ALDH} 1^{\text {high }}$ and $\mathrm{ALDH} 1^{\text {low }}$ cells were examined for statistical significance using Student's $t$-test. ${ }^{*}$-values. (c) Sphere formation assay. Numbers of spheres from ALDH $1^{\text {high }}$ and ALDH $1^{\text {low }}$ cells were counted on day 7. Data represent means \pm s.d. The differences were examined for statistical significance using Student's t-test. ${ }^{*} P$-values. Representative sphere pictures are shown in the right panel $(\times 100)$. (d) RT-PCR for stem cell markers. Expression of stem cell marker genes was analyzed by RT-PCR. GAPDH was used as an internal control. High: $\mathrm{ALDH} 1^{\text {high }}$ cells, low: ALDH $1{ }^{\text {low }}$ cells. (e) Quantitative real-time PCR for stem cell markers. Expression of stem cell marker genes was analyzed by quantitative real-time PCR. 
FGF4 expression level and CAFs ratio was analyzed in Excel 2010. Each multivariate analysis was performed with the stepwise method. In all analysis, $P$-values $<0.05$ were considered as statistically significant.

\section{RESULTS \\ CSCs/CICs are Enriched in the ALDH1 ${ }^{\text {high }}$ Population of Ovarian Carcinoma HTBoA Cells}

Several methods for isolating CSCs/CICs, including Hoechst33342 assay, ALDEFLUOR assay and use of cell surface markers (ie, CD44 and CD133), have been reported. ${ }^{4}$ In our previous study, we found that CSCs/CICs of ovarian carcinoma MCAS cells were enriched in an aldehyde dehydrogenase high activity population $\left(\mathrm{ALDH} 1^{\text {high }}\right)$ by the ALDEFLUOR assay as well as in a side population by the Hoechst33342 assay. ${ }^{16,17}$ Therefore, we sorted out ALDH1 $1^{\text {high }}$ cells and ALDH1 ${ }^{\text {low }}$ cells from ovarian carcinoma HTBoA cells by the ALDEFLUOR assay (Figure 1a). The ratio of ALDH1 ${ }^{\text {high }}$ cells was $8.8-10.8 \%$ in three independent experiments. ALDH $1^{\text {high }}$ cells exhibited significantly higher tumor-forming ability ( 3 of 5 mice) than did ALDH1 $1^{\text {low }}$ cells (0 of 5 mice) when they were inoculated into NOD/SCID mice (Figure 1b; Table 1). ALDH1 $1^{\text {high }}$ cells exhibited significantly higher sphere-forming capacity in culture with serum-free medium (Figure 1c) and higher expression levels of stem cell markers (SOX2, POU5F1, NANOG and CD44) than did ALDH1 $1^{\text {low }}$ cells (Figures 1d and e). These results indicate that CSCs/CICs of HTBoA cells are enriched in ALDH1 ${ }^{\text {high }}$ cells.

Table 1 Tumor-initiating capacity of HTBoA ovarian cancer cells

Number of mice with tumor formation ${ }^{\mathrm{a}}$ /

Total number of mice (injected cell number)

\begin{tabular}{lccc} 
Cells & $10^{2}$ & $10^{3}$ & $10^{4}$ \\
\hline HTBOA & & & \\
ALDH1 ${ }^{\text {high }}$ cells & $0 / 5$ & $0 / 5$ & $3 / 5$ \\
ALDH1 $1^{\text {low }}$ cells & $0 / 5$ & $0 / 5$ & $0 / 5$ \\
\hline
\end{tabular}

${ }^{\mathrm{a}}$ Tumor formation was evaluated at day 70 post inoculation.

\section{Normal Fibroblasts Enhanced the Tumorigenic Capacity and CAF Induction in CSC/CIC-Derived Tumors of HTBoA Cells}

It has been reported that CAFs could induce epithelialmesenchymal transition and cancer stemness in prostate carcinoma PC3 cells. ${ }^{18}$ We therefore examined whether fibroblasts can affect the tumorigenic capacity of CSCs/CICs of ovarian cancer cells. Ten thousand ALDH $1^{\text {high }}$ cells with or without a mixture of normal skin fibroblasts (N25-5) were inoculated into NOD/SCID mice (Figure 2a). Fibroblastmixed $\mathrm{ALDH} \mathrm{1}^{\text {high }}$ cells showed a higher tumor incidence (5 of 5) and formed significantly larger tumors than did $\mathrm{ALDH} 1{ }^{\text {high }}$ cells without a mixture of fibroblasts (Figure $2 \mathrm{~b}$; Table 2). Neither ALDH1 ${ }^{\text {low }}$ only cells nor fibroblast-mixed ALDH $1^{\text {low }}$ cells exhibited tumor formation in five mice (Table 2). Histological examination revealed that fibroblastmixed ALDH $1^{\text {high }}$ tumor tissues contained abundant fibrous stroma, whereas ALDH1 $1^{\text {high }}$ only tumor tissues contained few stroma (Figures $2 \mathrm{c}$ and d). The stromal fibroblasts were negative for HLA class I and positive for $\alpha$-SMA by immunohistochemical examination, indicating that they were CAFs derived from recipient mouse (Figure 2d). Similar results were confirmed by the experiments using another fibroblasts (N30-3) (Supplementary Figure 1). Next, we examined in vitro sphere formation capacity of ALDH1 $1^{\text {high }}$ and ALDH1 $1^{\text {low }}$ cells in the presence or absence of fibroblasts (Figure 3). ALDH1 ${ }^{\text {high }}$ cells exhibited significantly higher sphere formation capacity in the presence of fibroblasts than those without fibroblasts or ALDH1 ${ }^{\text {low }}$ cells. Mixture of fibroblasts could not enhance the sphere formation capacity of ALDH $1^{\text {low }}$ cells. SMA-positive fibroblasts were observed in peripheral region of the spheres derived from HTBoA mixed with fibroblasts. These data indicate that normal fibroblasts promote the tumor-initiating capacity and CAF induction capacity of CSCs/CICs, but not those of non-CSCs/CICs.

\section{Cancer Stemness Genes were Upregulated in a Fibroblast-Mixed ALDH1 $1^{\text {high }}$ Tumor}

Tumor-initiating capacity, as determined by an in vivo tumor formation assay and an in vitro sphere formation assay, is a hallmark of CSCs/CICs and is closely associated with the expression of cancer stemness genes such as SOX2, POU5F1 and NANOG. DNAJB8 is a newly identified CSC-related gene that controls tumor-initiating ability in renal CSCs. ${ }^{19}$

\footnotetext{
Figure 2 In vivo tumor formation assay of $\mathrm{ALDH} 1^{\text {high }}$ cells in the presence or absence of fibroblasts. (a) Schema of cell transplantation into NOD/SCID mice. $1 \times 10^{4} \mathrm{ALDH} 1^{\text {high }}$ cells with or without a mixture of $1 \times 10^{4}$ human normal skin fibroblasts (N25-5) were suspended in $100 \mu$ l of PBS matrigel mixture and inoculated into NOD/SCID mice. (b) Tumor formation assay. Fibroblast-mixed ALDH $1^{\text {high }}$ cells developed earlier and significantly larger tumors than did ALDH $1^{\text {high }}$ only cells. Data represent means \pm s.d. Differences between fibroblast-mixed ALDH $1^{\text {high }}$ tumor and ALDH $1^{\text {high }}$ only tumor were examined for statistical significance using Student's t-test. ${ }^{*} P$-values. (c) HE staining of ALDH $1{ }^{\text {high }}$ only tumor. Representative picture of hematoxylin and eosin staining of tumor tissue. $\times 200$ magnification. (d) HE staining and immunostaining of fibroblast-mixed ALDH $1^{\text {high }}$ tumor. Upper panel: Representative picture of hematoxylin and eosin staining of the tumor tissue. Abundant CAFs are induced in tumor tissue. $\times 100$ magnification. Middle panel: Immunostaining with anti-HLA class I antibody. Tumor cells are positive for HLA, but stromal cells are negative. $\times 100$ magnification. Lower panel: Immunostaining with anti- $\alpha$-SMA antibody. Stromal fibroblasts are positive for $\alpha$-SMA. $\times 100$ magnification.
} 
a

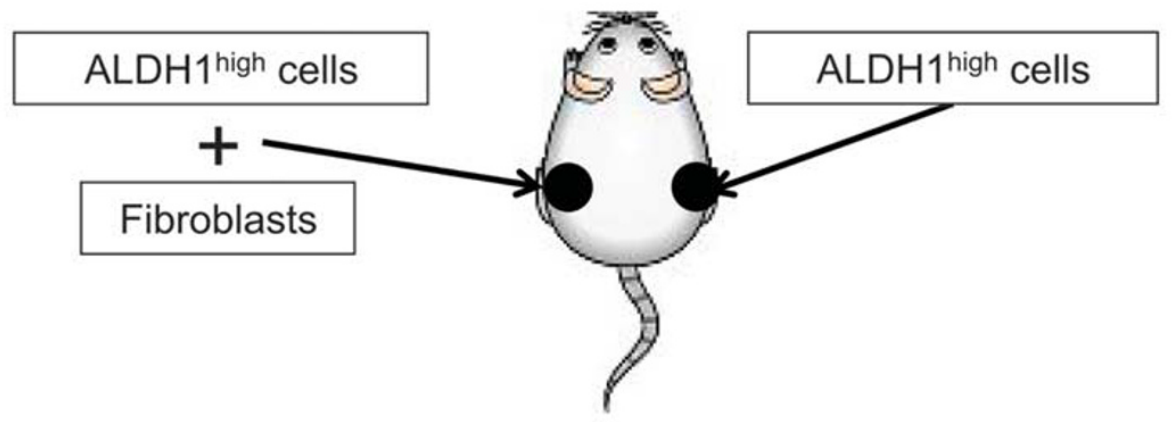

b

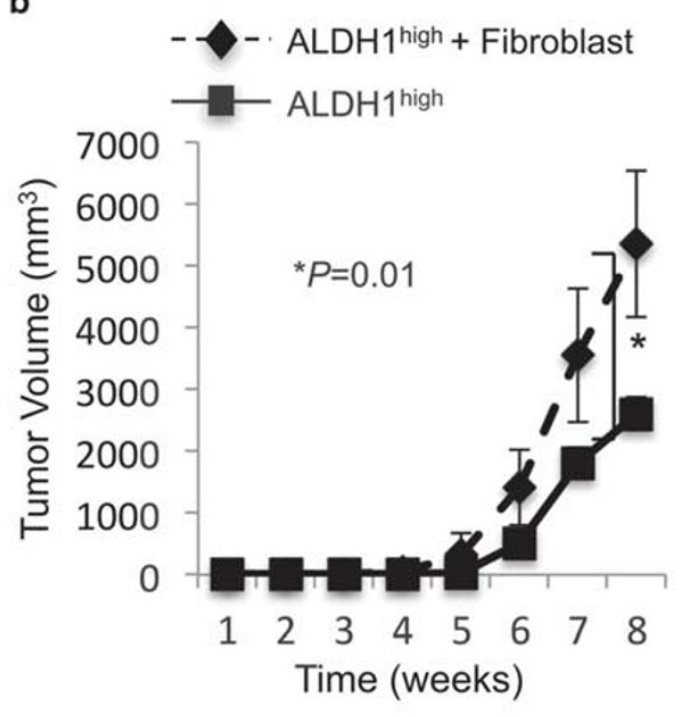

d

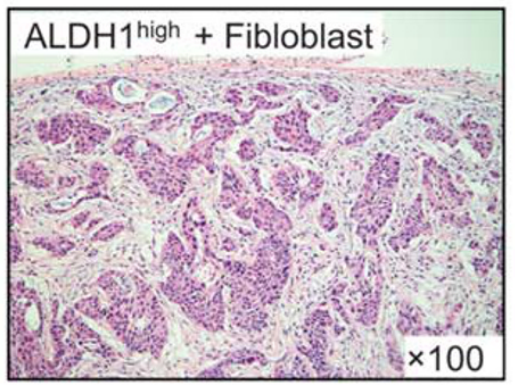

C

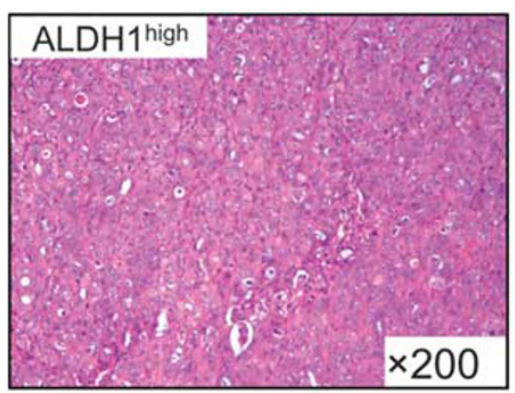

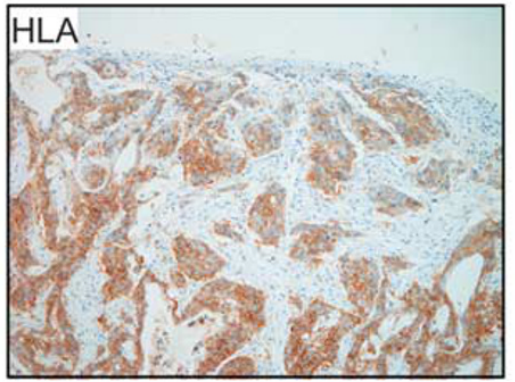

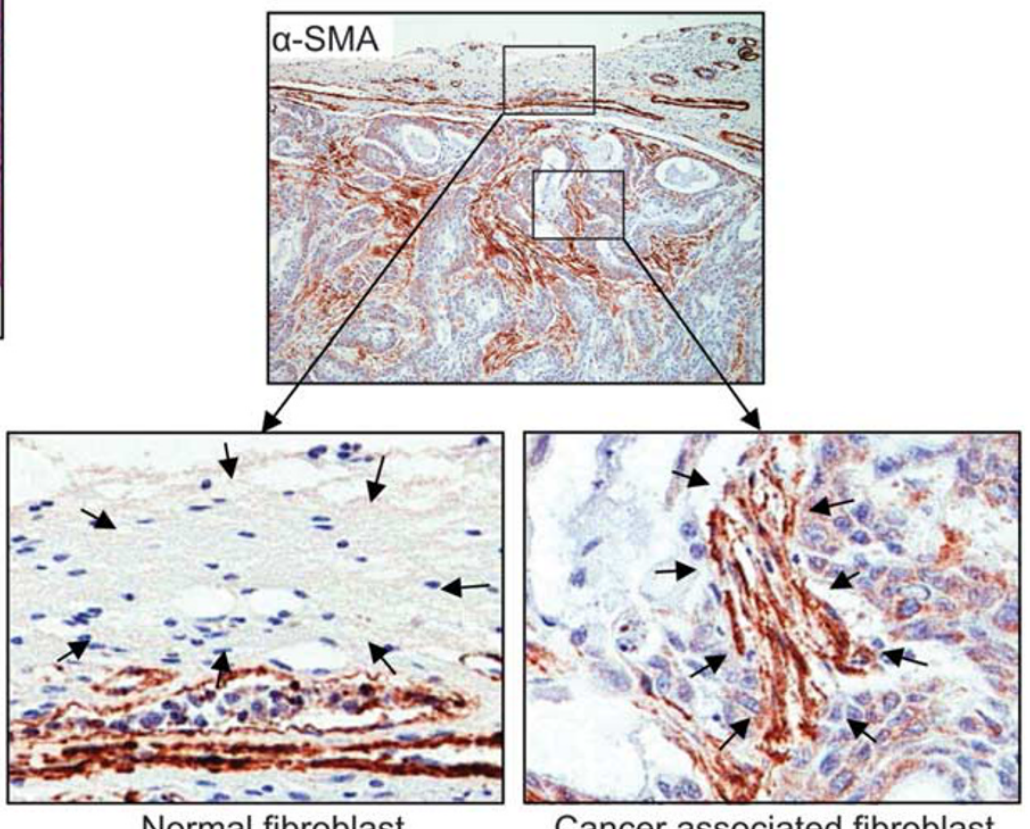

Cancer associated fibroblast 
Table 2 Tumor-initiating capacity of HTBoA cells in the presence or absence of fibroblasts

\begin{tabular}{lc} 
Cells & $\begin{array}{c}\text { Number of mice with tumor } \\
\text { formation }{ }^{\text {a }} / \text { Total number of mice }\end{array}$ \\
\hline Fibroblast-mixed ALDH1 ${ }^{\text {high }}$ cells & $5 / 5$ \\
ALDH1 $^{\text {high }}$ cells & $3 / 5$ \\
Fibroblast-mixed ALDH1 ${ }^{\text {low }}$ cells & $0 / 5$ \\
ALDH1 ${ }^{\text {low }}$ cells & $0 / 5$ \\
Fibroblasts & $0 / 5$ \\
\hline
\end{tabular}

$10^{4}$ tumor cells were inoculated with or without a mixture of $10^{4}$ fibroblasts. ${ }^{a}$ Tumor formation was evaluated at day 70 post inoculation.

Therefore, expression levels of these cancer stemness genes were examined by quantitative real-time PCR. CSC/CIC-related genes were upregulated in fibroblast-mixed ALDH 1 high tumors (Figure 4a). Protein levels of SOX2 and ALDH1 were also increased in fibroblast-mixed ALDH1 $1^{\text {high }}$ tumor tissues as detected by immunohistochemical staining (Figure 4b).

\section{FGF4 Gene Expression was Induced in ALDH1 ${ }^{\text {high }}$ Cells after Mixing with Fibroblasts}

To determine the differences between gene expression in CSC/CIC-derived tumors with CAFs (fibroblast-mixed ALDH1 ${ }^{\text {high }}$ tumors) and those without CAFs (ALDH1 $1^{\text {high }}$ only tumors), comparative gene expression analysis was performed by RT-PCR. Previous report presented that FGF family might be involved with stromal induction of cancer. ${ }^{20}$ The expression levels of four FGF family genes (FGF3, FGF4, FGF5 and FGF6) that are related to oncogenesis were addressed, in tumor samples derived from fibroblast-mixed ALDH $1^{\text {high }}$ cells, and only ALDH $1^{\text {high }}$ cells (Figure 5a). Fibroblast line cells were also used as a control. FGF3, FGF5 and FGF6 were undetectable in tumors derived from fibroblast-mixed ALDH1 $1^{\text {high }}$ cells, and only ALDH $1^{\text {high }}$ cells. Whereas, FGF4 was detected in tumor derived from fibroblast-mixed ALDH1 $1^{\text {high }}$ cells; however, FGF4 was undetectable in tumor derived from only ALDH1 ${ }^{\text {high }}$ cells. The data suggested that FGF4 was a candidate for stromal induction. FGF4 is not only a growth factor for fibroblasts but also an oncogenic growth factor that has potential to transform mice embryonal fibroblasts. ${ }^{21}$ Therefore, we further analyzed the expression levels of FGF4 and its related genes by RT-PCR. As shown in Figure 5b, expression of FGF4 was upregulated in fibroblast (N25-5)-mixed ALDH1 ${ }^{\text {high }}$ tumors compared with the expression in ALDH $1{ }^{\text {high }}$ only tumors. Similar results were obtained from another fibroblast (N30-3)-mixed ALDH $1{ }^{\text {high }}$ tumor (Supplementary Figure 1). The expression levels of FGF4 receptor (FGFR2), TGF- $\beta$ signaling molecules (TGFB1 and SMAD2) and inflammatory signaling molecules (IL-1B and STAT3) were also higher in fibroblast-mixed
ALDH1 ${ }^{\text {high }}$ tumors than in ALDH1 ${ }^{\text {high }}$ only tumors. FGF4 gene expression level was also increased after co-culture of $\mathrm{ALDH} 1^{\text {high }}$ cells with fibroblasts, although FGFR2 expression level was not changed (Figure $5 \mathrm{c}$ ). In contrast to ALDH1 $1^{\text {high }}$ cells, ALDH $1{ }^{\text {low }}$ cells barely expressed FGFR2, and FGF4 gene expression was not detected even after co-culture with fibroblasts (Figure 5c). In Figure 5d, positivity to anti-FGF4 and anti-FGFR2 antibody was extremely high in tumors derived from fibroblast-mixed ALDH1 ${ }^{\text {high }}$ cells compared with that in tumors derived from ALDH $1^{\text {high }}$ cells.

\section{FGF4-FGFR2 Signaling has an Important Role in the Sphere-Forming Capacity of Fibroblast-Mixed ALDH $1^{\text {high }}$ Cells}

To determine the significance of FGF4 gene expression in the mechanism of fibroblast-induced cancer stemness in $\mathrm{ALDH} 1^{\text {high }}$ cells, we examined the sphere-forming capacity in the presence of recombinant human FGF4. FGF4 significantly enhanced the sphere-forming capacity of ALDH1 $1^{\text {high }}$ cells but not that of ALDH1 $1^{\text {low }}$ cells (Figure 6a). These results are consistent with the findings that the FGF4 receptor is expressed on ALDH $1^{\text {high }}$ cells but is expressed at a very low level on ALDH1 ${ }^{\text {low }}$ cells (Figure 5c). Next, we examined the effect of FGFR2 knockdown on the sphere-forming capacity of ALDH1 $1^{\text {high }}$ cells in the presence or absence of fibroblasts. The sphere-forming capacity of ALDH ${ }^{\text {high }}$ cells was dramatically suppressed by knockdown of FGFR2 even in the absence of fibroblasts (Figure 6b). These results indicate that FGFR2 is crucial not only for the fibroblast-induced sphereforming capacity of CSCs/CICs but also for the basal sphereforming capacity in the absence of fibroblasts. FGFR2 is known to function as a receptor for several FGF family growth factors. Indeed, the sphere culture medium contained FGF2 (bFGF), for which FGFR2 acts as a receptor.

\section{Soluble Factors Released from Fibroblasts can Promote the Sphere-Forming Capacity of ALDH1 ${ }^{\text {high }}$ Cells}

To determine whether cell-to-cell contact is required for the promotion of sphere formation, we collected fibroblast culture supernatant and examined the activity. Normal human fibroblasts were cultured in CSC Certified $^{\mathrm{TM}}$, Complete Serum-Free Medium for 2 days. Then, the supernatant was added to the sphere culture. As shown in Figure 7, fibroblast culture supernatant enhanced the sphere-forming capacity of $\mathrm{ALDH} 1^{\text {high }}$ cells but not that of ALDH ${ }^{\text {low }}$ cells. These results indicate that cell-to-cell contact between fibroblasts and CSCs/CICs is not required and that soluble factors released from fibroblasts have activity for enhancing the sphere formation capacity of CSCs/CICs of HTBoA cells.

\section{High Expression Levels of FGF4 are Associated with Poor Prognosis}

A total 122 of epithelial ovarian cancer tissues were immunohistochemically stained with anti-FGF4 antibody and counted the positivity of staining. We divided into three groups 

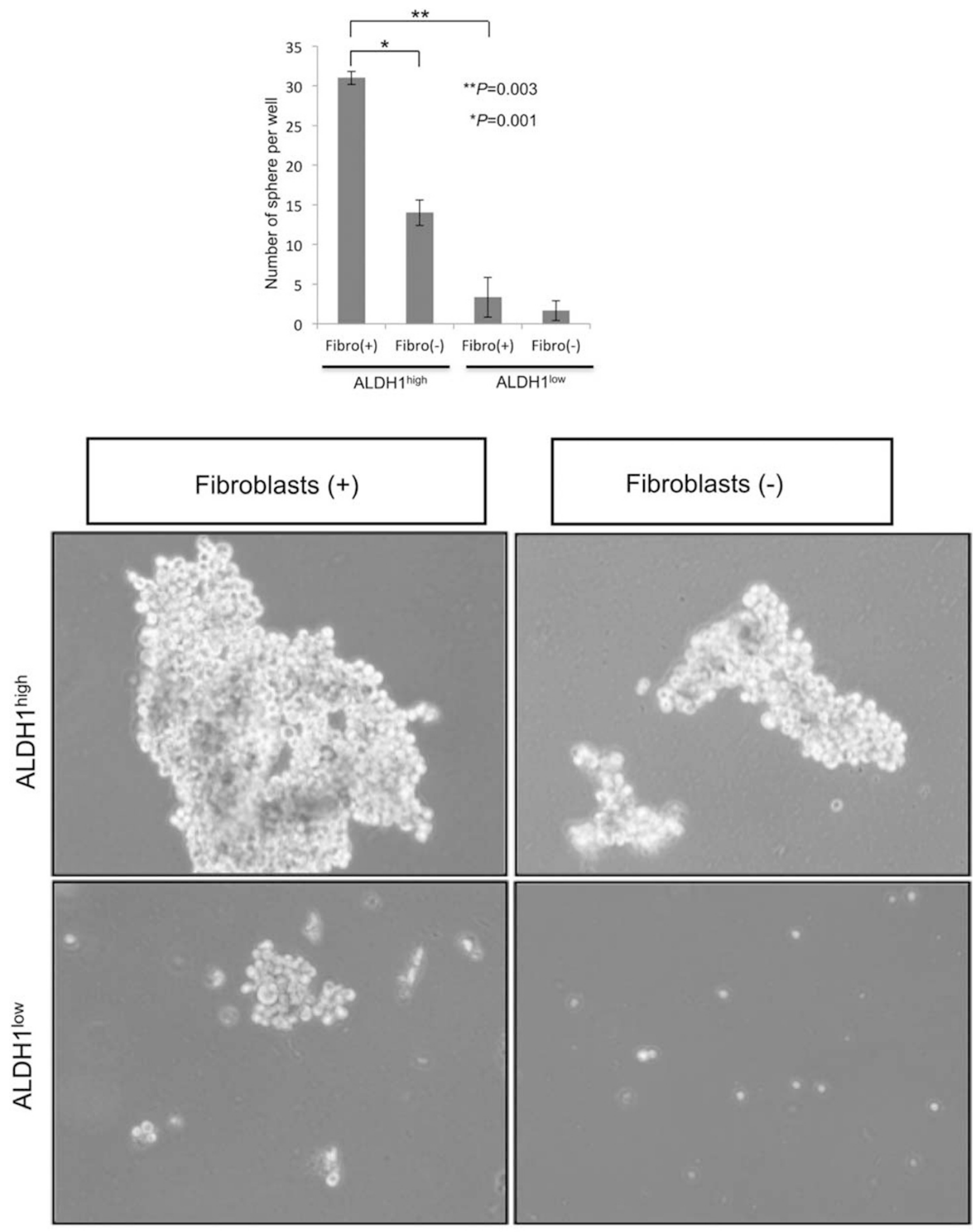

(X100)

Figure 3 Sphere formation assay in the presence or absence of fibroblasts. Sphere numbers of four groups (fibroblast-mixed ALDH1 ${ }^{\text {high }}$ cells, $A L D H 1^{\text {high }}$ only cells, fibroblast-mixed $A L D H 1^{\text {low }}$ cells, ALDH $1^{\text {low }}$ only cells) were evaluated at day 7 . Data represent means $\pm s . d$. The differences were examined for statistical significance using Student's $t$-test. ${ }^{*} P$-values. Representative sphere pictures are shown in the lower panel $(\times 100)$. 


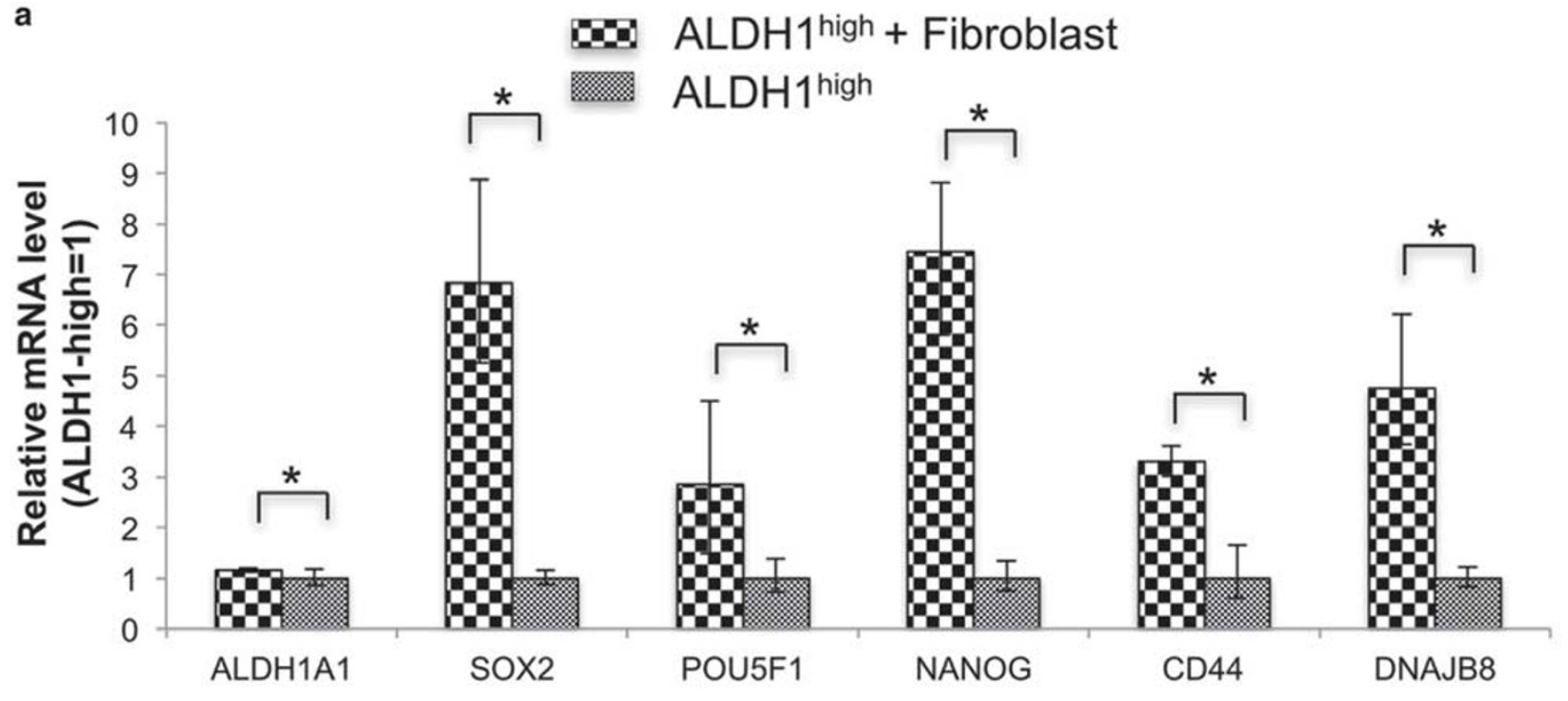

b

$\mathrm{ALDH} 1^{\text {high }}+$ Fibroblast

ALDH1 $1^{\text {high }}$
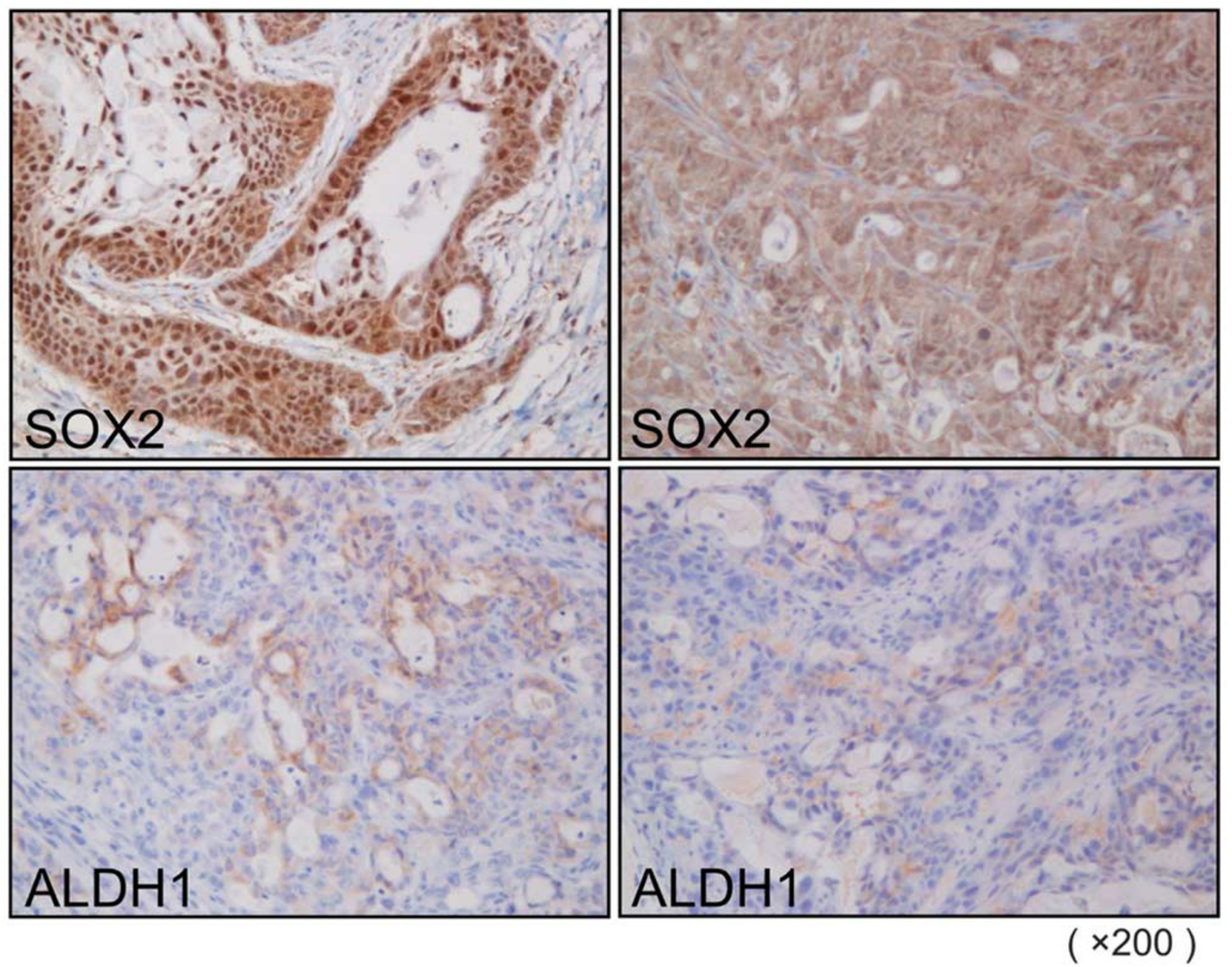

Figure 4 RT-PCR and immunostaining of tumor tissues. (a). Quantitative real-time PCR for stem cell markers. Expression of stem cell marker genes was analyzed by RT-PCR. GAPDH was used as an internal control. (b) Immunostaining for SOX2 and ALDH1. SOX2 (upper panels) and ALDH1 (lower panels) were detected by immunostaining with specific antibodies. $\times 200$ magnification. 
a

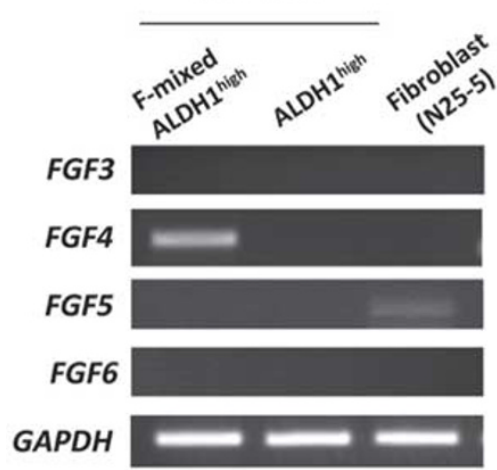

b

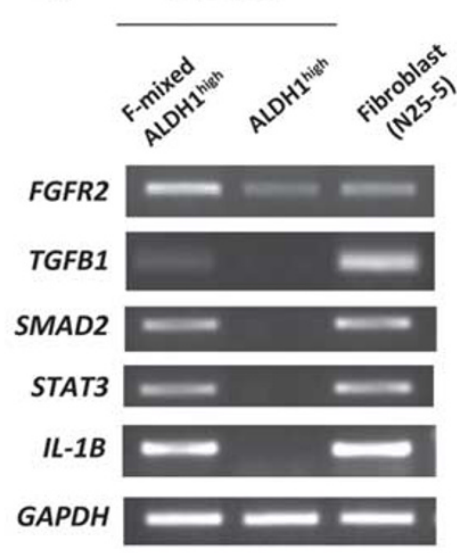

c

F-mixed
ALDH1
high

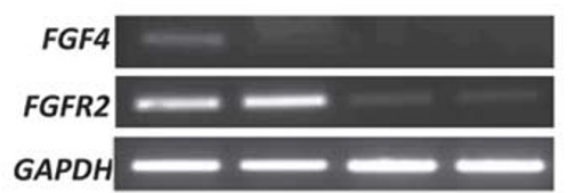

d ALDH1 $1^{\text {high }}+$ Fibroblast
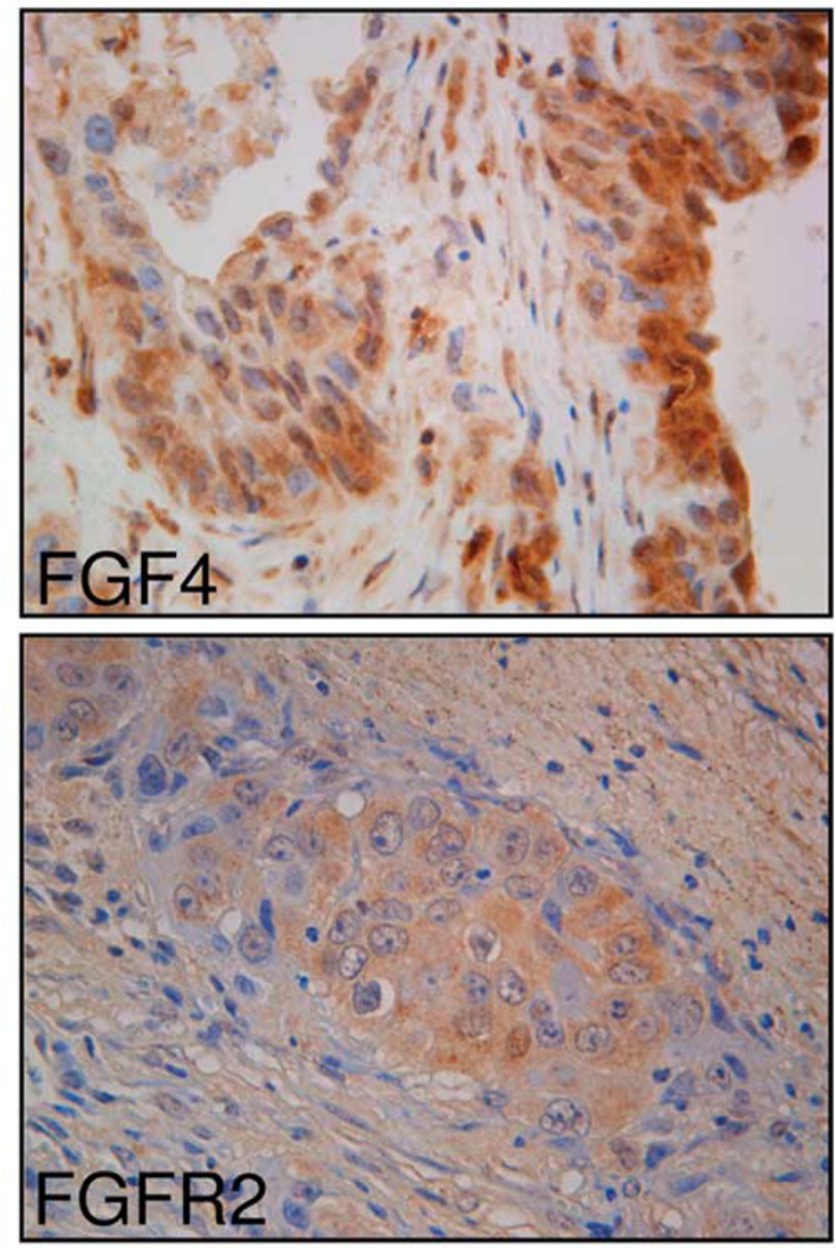
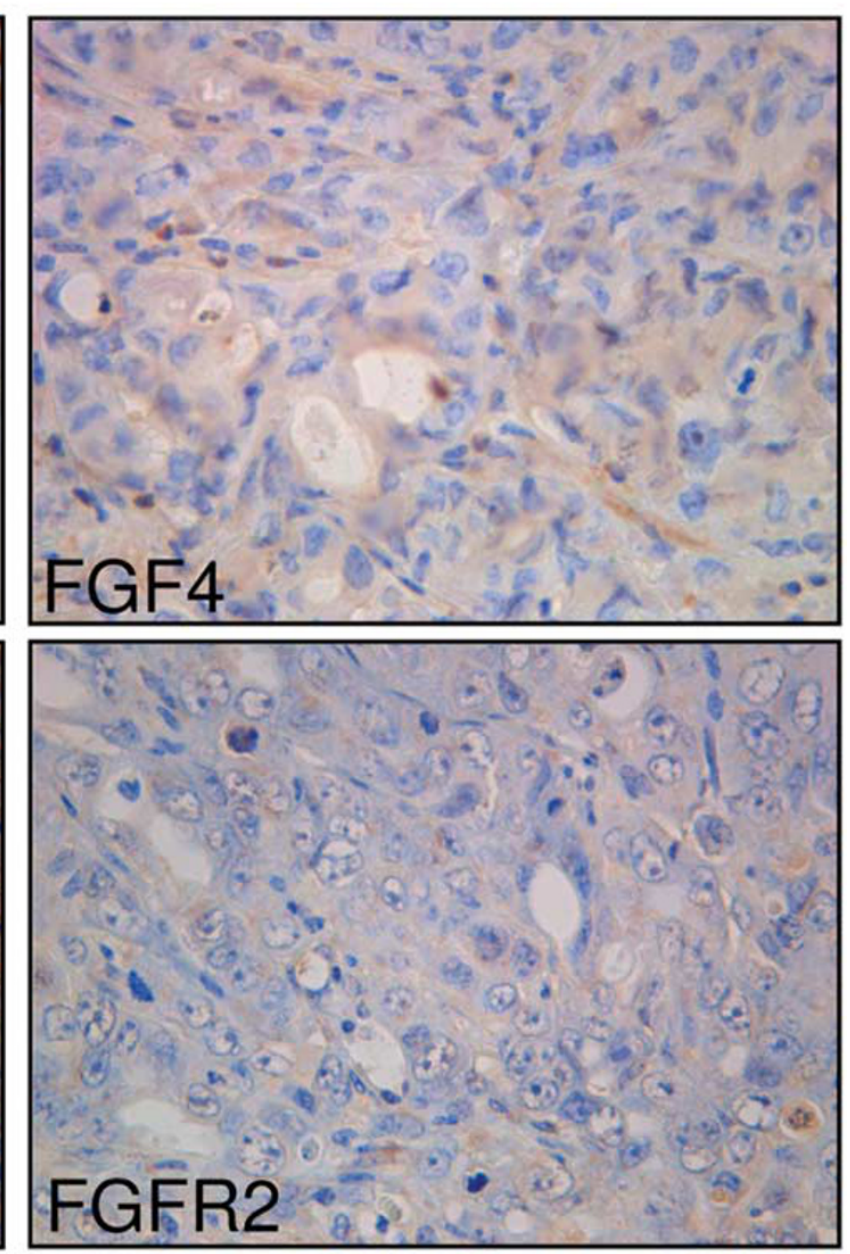

$(\times 200)$

Figure 5 RT-PCR for FGF4 and its related genes. (a) Gene expression analysis of FGF family. Gene expression in tumor samples and normal skin fibroblasts was analyzed by RT-PCR. GAPDH was used as an internal control. (b) Gene expression analysis with tumor samples and fibroblasts. Gene expression in tumor samples and normal skin fibroblasts was analyzed by RT-PCR. GAPDH was used as an internal control. (c) Gene expression analysis with in vitro cultured cells. Gene expression in four groups of in vitro cultured cells (fibroblast-mixed ALDH $1^{\text {high }}$ cells, ALDH $1^{\text {high }}$ only cells, fibroblastmixed ALDH1 $1^{\text {low }}$ cells, ALDH1 ${ }^{\text {low }}$ only cells) was analyzed by RT-PCR. GAPDH was used as an internal control. (d) Immunostaining for FGF4 and FGFR2. FGF4 (upper panels) and FGFR2 (lower panels) were detected by immunostaining with specific antibodies. $\times 200$ magnification. 
a

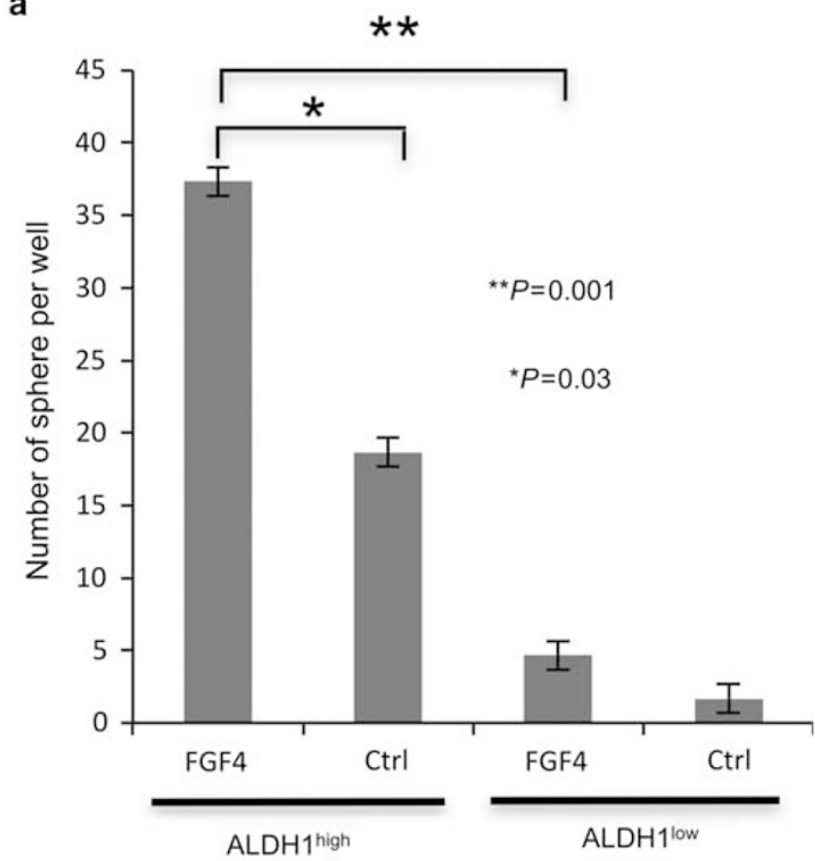

b

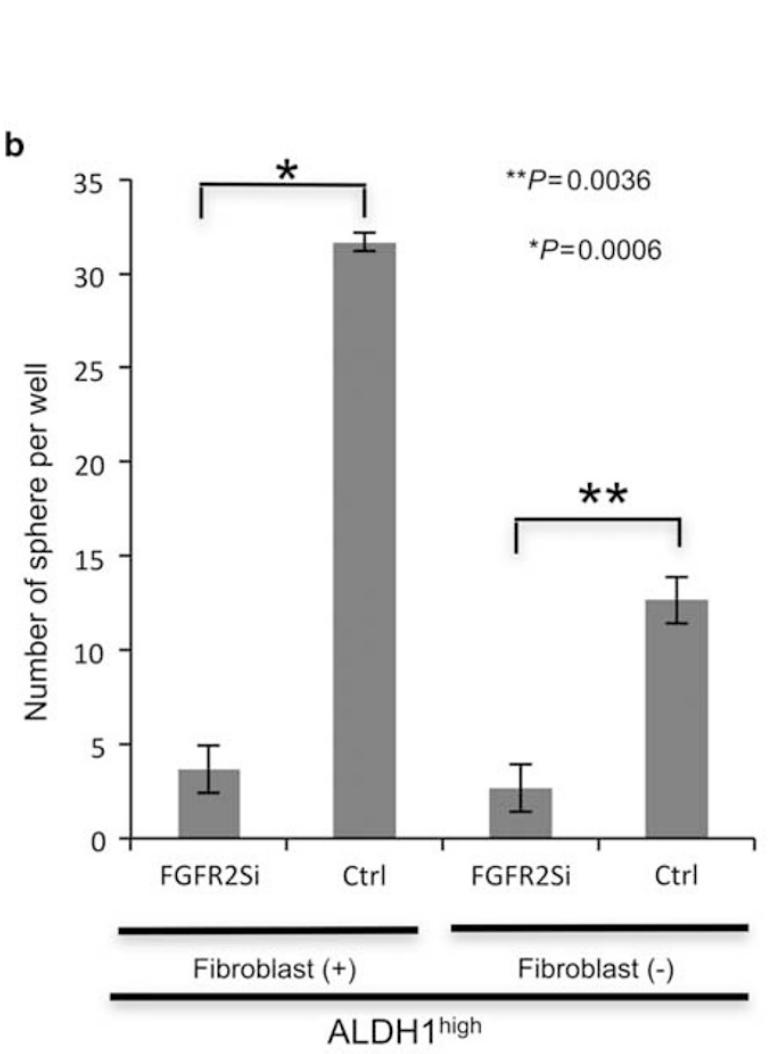

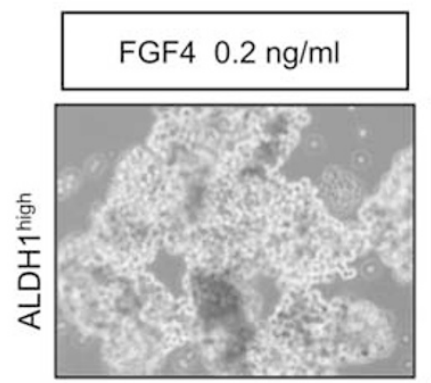
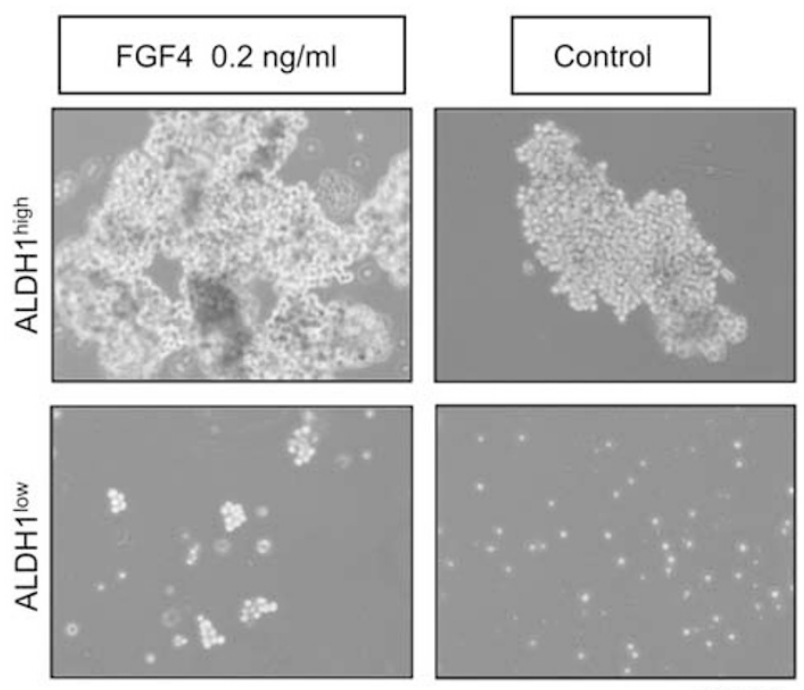

$(\mathrm{X} 100)$

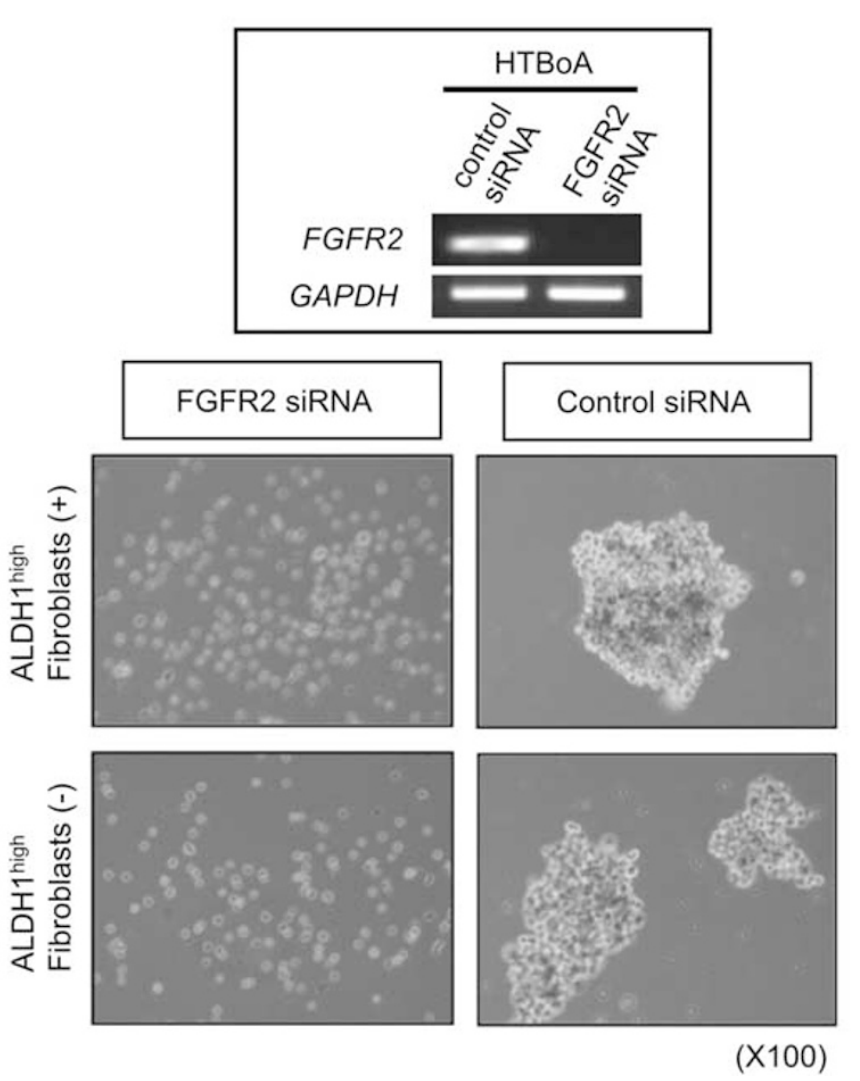

Figure 6 Sphere formation assay with recombinant FGF4 and FGFR2-siRNA. (a) Sphere formation assay with recombinant FGF4. Sphere-forming capacity of $A L D H 11^{\text {high }}$ cells and that of $A L D H 11^{\text {low }}$ cells were assessed. Recombinant human FGF4 was added to the sphere formation assay culture medium to a final concentration of $0.2 \mathrm{ng} / \mathrm{ml}$. Data represent means \pm s.d. The differences were examined for statistical significance using Student's t-test. ${ }^{*}$-values. Ctrl: PBS only. Representative sphere pictures are shown in the right panels $(\times 100)$. (b) Sphere formation assay with FGFR2 gene knockdown. Sphere-forming capacity was assessed after siRNA-mediated FGFR2 gene knockdown in ALDH1 high cells with or without a mixture of fibroblasts. Data represent means \pm s.d. The differences were examined for statistical significance using Student's $t$-test. ${ }^{*} P$-values. FGFR2Si: FGFR2-siRNA, Ctrl: control siRNA. FGFR2 gene knockdown was confirmed by RT-PCR (right upper panel). Representative sphere pictures are shown in the right lower panels $(\times 100)$. 

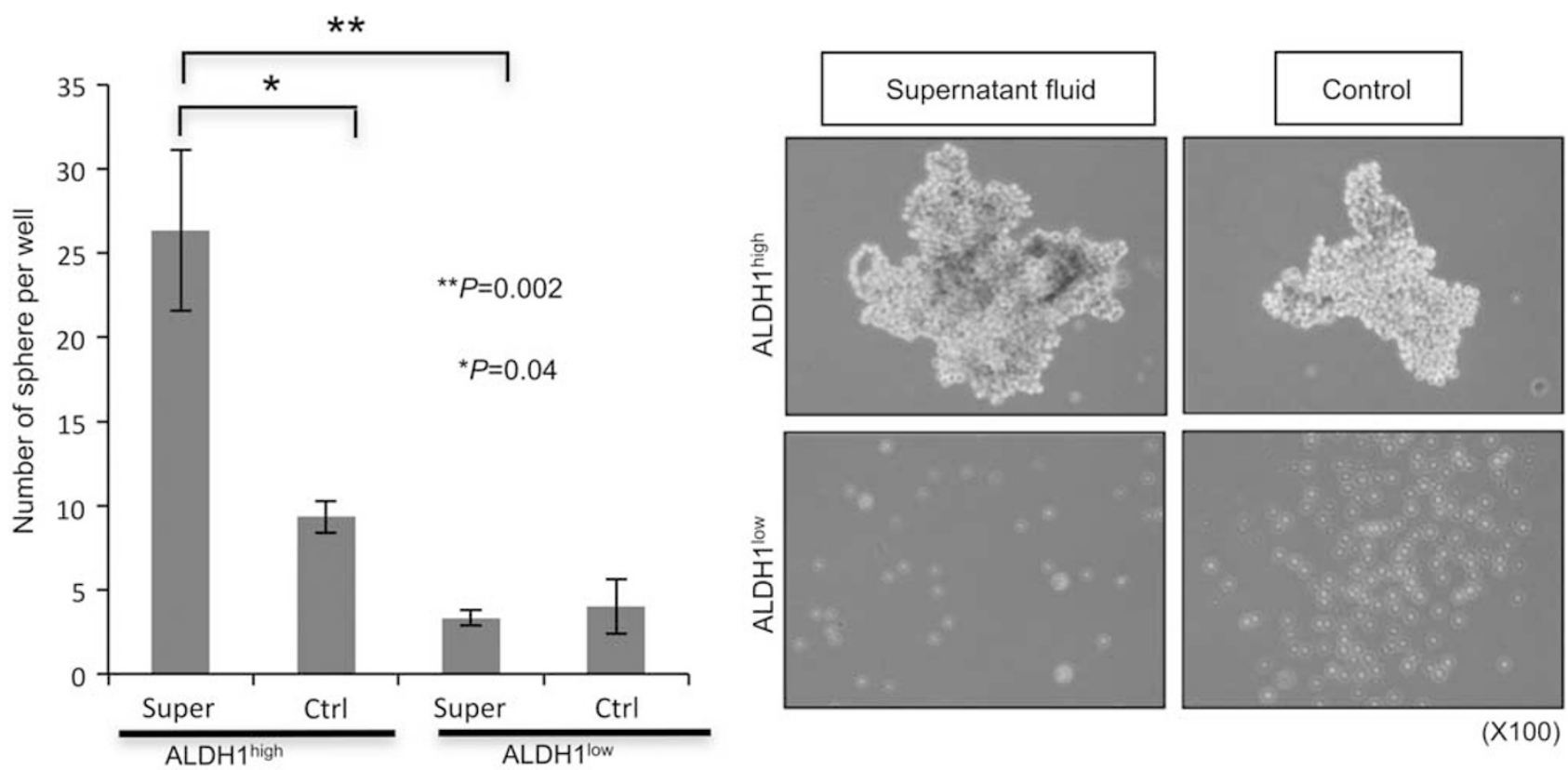

$(\mathrm{X} 100)$

Figure 7 Sphere formation assay with fibroblast culture supernatant. Sphere-forming capacity of ALDH1 ${ }^{\text {high }}$ cells and that of ALDH $1^{\text {low }}$ cells were assessed. Fibroblast culture supernatant was added to the sphere formation assay culture medium to a final concentration of $50 \%$. Data represent means \pm s.d. The differences were examined for statistical significance using Student's $t$-test. ${ }^{*} P$-values. Super: $50 \%$ fibroblast culture supernatant, $C$ trl: medium only. Representative sphere pictures are shown in the right panels $(\times 100)$.

Table 3 Immunohistochemical analysis in 122 epithelial ovarian cancer tissues

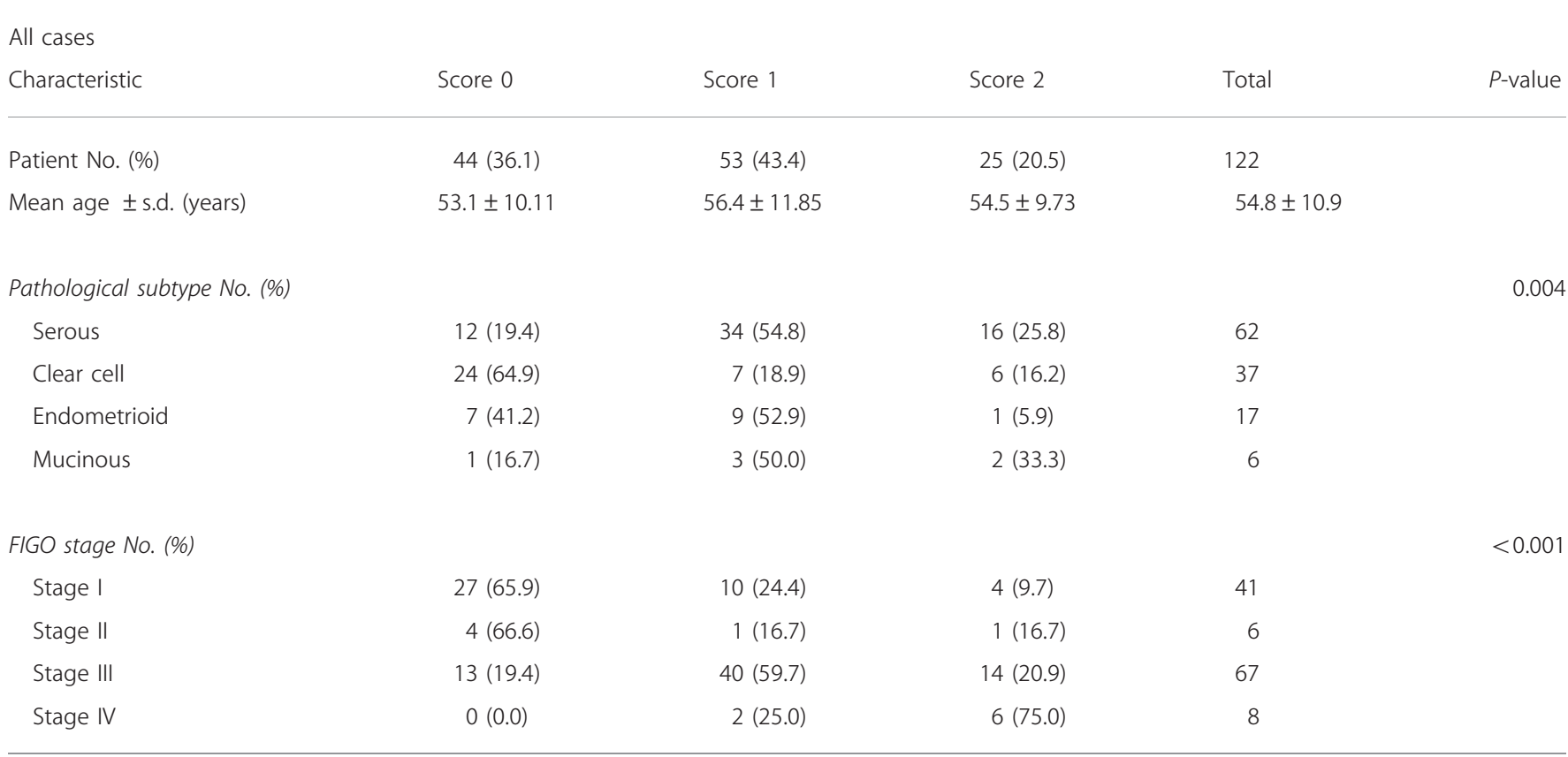

(Table 3; Figure 8a): Score 0 (FGF4 positivity; $<5 \%$ ), Score 1 (FGF4 positivity; $>5 \%,<10 \%)$ and Score 2 (FGF4 positivity; $>10 \%)$. The data were summarized in Table 3. FGF4 score 0 is significantly less in serous adenocarcinoma cases, and FGF4 score 1 is significantly higher in serous adenocarcinoma cases $(P=0.004)$. FGF4 score 0 is correlated with FIGO Stage I and score 2 is correlated with FIGO Stage IV $(P<0.001)$. The high expression of ALDH1 was correlated with poorer prognosis in previous study. ${ }^{16}$ The correlation of FGF4 expression and ALDH1 expression was analyzed. There 
a

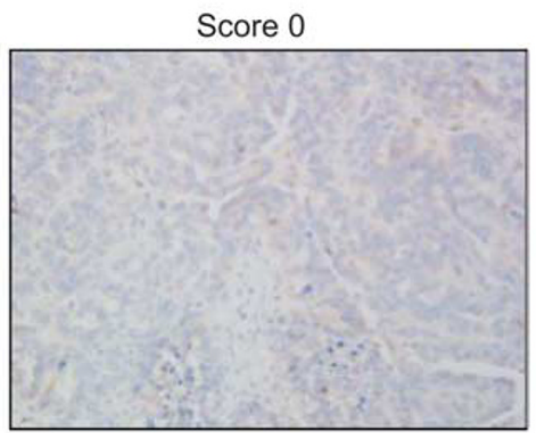

positivity less than $5 \%$
Score 1

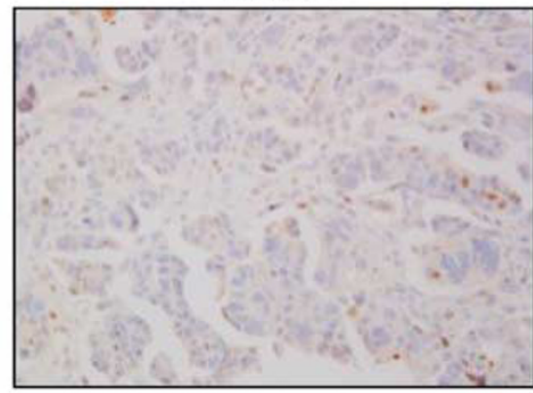

positivity 5-10\%
Score 2

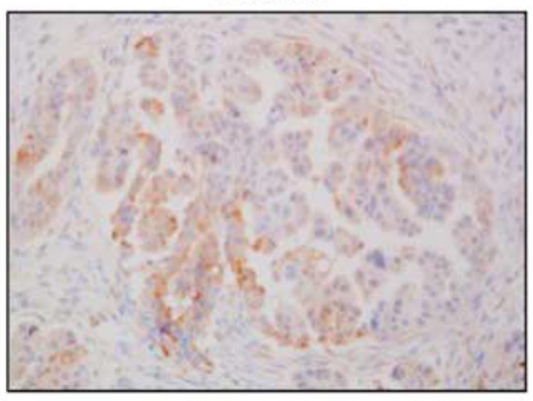

positivity more than $10 \%$ b

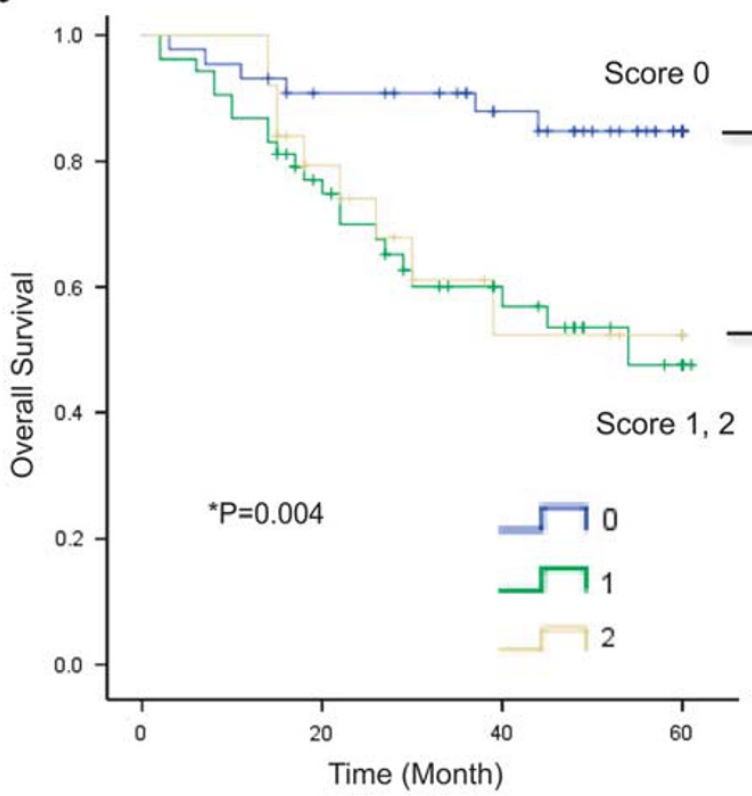

C
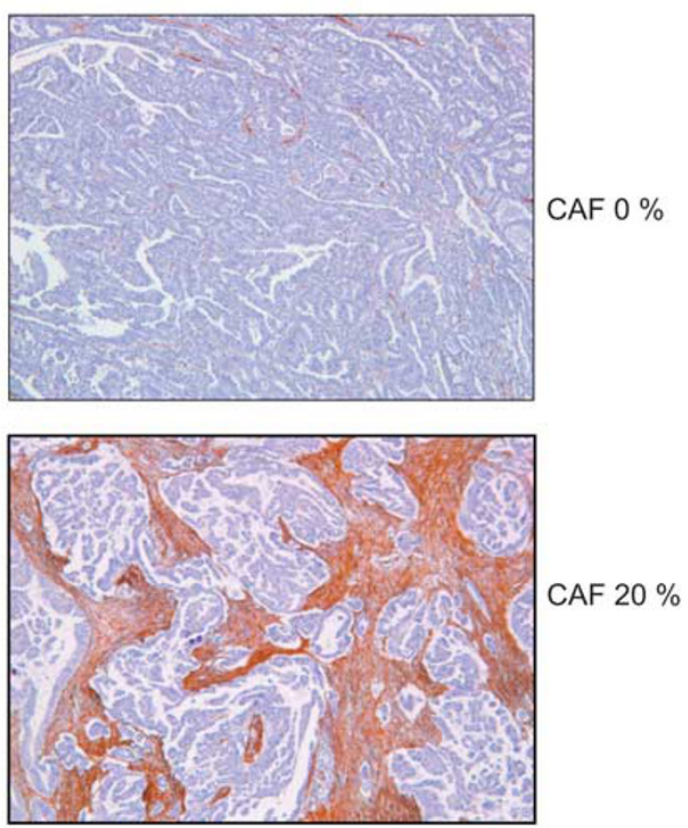

d

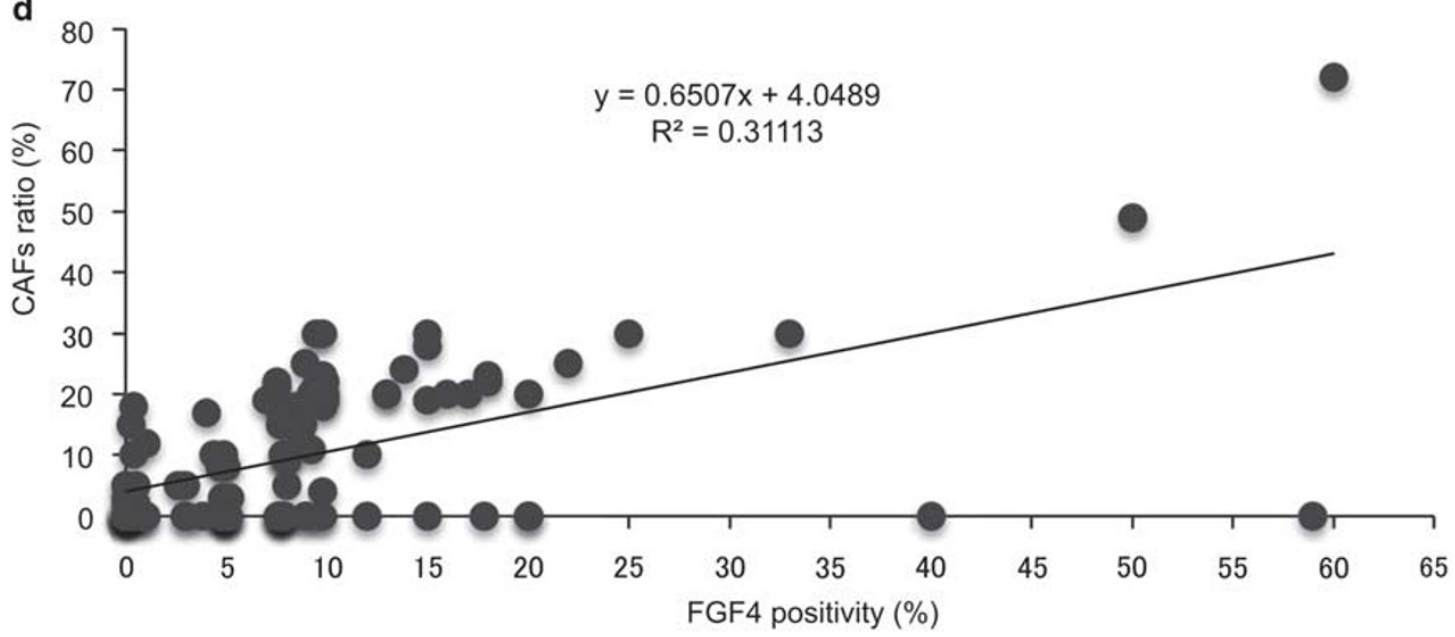

Figure 8 Correlation between FGF4 immunoreactivity and patients' clinical outcome or CAFs proportion. FGF4 immunoreactivity is associated with poor prognosis. (a) A total 122 of epithelial ovarian cancer tissues were immunohistochemically stained with anti-FGF4 antibody and scored by three groups according to the positivity of staining. (b) The differences of overall survival were examined for statistical significance using Fischer's test. * $P$-values. FGF4 immunoreactivity and CAFs ratio have certain correlation. (c) A total of 122 epithelial ovarian cancer tissues were stained with $\alpha$-SMA antibody. (d) Each CAFs ratio and FGF4 positivity rate were plotted and their correlation coefficient was analyzed by CORREL function. 
were weak but significant correlation between FGF4-positive rates and ALDH1-positive rates $(r=0.234, P=0.009)$ (Supplementary Figure 3$)$. In Figure $8 \mathrm{~b}, \log$-rank test revealed that higher expression of FGF4 (Score 1 and Score 2) is associated with poorer prognosis with a significant difference than those of lower expression levels of FGF4 $(P=0.004)$. Higher expression levels of FGF4 showed tendency with shorter PFS than those of lower expression levels of FGF4.

\section{The Expression Level of FGF4 and the Ratio of CAFs Have Certain Correlation}

A total 122 of epithelial ovarian cancer tissues were also stained with $\alpha$-SMA antibody and counted the positivity of staining as the ratio of CAFs (Figure 8c). The ratio of CAF and FGF4 positivity rate were plotted and correlation coefficient was analyzed by CORREL function (Figure 8d). Correlation coefficient is 0.56 . The expression level of FGF4 and the ratio of CAFs are associated with significant correlation $(P<0.01)$.

\section{DISCUSSION}

The cancer microenvironment has critical roles in cancer initiation, progression, invasion and metastasis, and CAF is a major component of the cancer microenvironment. ${ }^{6}$ Actually, CAFs have roles in the adhesion and motility of tumor cells, and it is known that cancer cases with abundant CAFs have a poorer prognosis than that of cases with few CAFs. ${ }^{9,11}$ Importantly, recent studies have indicated that stem-like phenotypes are more interactive with the cancer microenvironment. Therefore, we examined the interaction between fibroblasts and CSCs/CICs.

In the present study, we first demonstrated that highly tumorigenic CSCs/CICs could be isolated in an ALDH1 ${ }^{\text {high }}$ population from HTBoA ovarian carcinoma cells. Previous studies showed successful isolation of ovarian CSCs/CICs by the ALDEFLUOR assay. ${ }^{22}$ Therefore, the ALDEFLUOR assay is a promising approach to isolate ovarian CSCs/CICs. We next examined the action of fibroblasts on the tumor initiation capacity of CSCs/CICs and the histology of tumors. ALDH1 $1^{\text {high }}$ tumors recruited prominent CAFs that were derived from recipient mice when inoculated with normal fibroblasts. Furthermore, a mixture with fibroblasts enhanced the expression of stem cell markers, in vivo tumor-initiating capacity and sphere-forming capacity of $\mathrm{ALDH}^{\text {high }}$ cells, indicating that cancer stem-like properties were upregulated by the action of fibroblasts.

RT-PCR analysis revealed that the FGF4 gene was expressed in fibroblast-mixed ALDH1 ${ }^{\text {high }}$ cells and tumor tissues. FGF4 is known to have a key role in maintaining the self-renewal potential of normal stem cells such as trophoblastic stem cells. ${ }^{23}$ Moreover, the role for FGF4 of tumor invasion have also speculated. ${ }^{23}$ We showed that FGF4 could enhance the sphere-forming capacity of ALDH1 ${ }^{\text {high }}$ cells, indicating that FGF4 might be one of the growth factors mediating the stemness-promoting action of fibroblasts on
CSCs/CICs. FGF4 was initially isolated as an oncogene that could transform NIH3T3 cells. ${ }^{20}$ FGF4 gene amplification has been reported in various human cancers. ${ }^{24-27}$ The FGF4 gene is expressed from the early stage of embryonic development in fetal life and has essential roles in cell differentiation, morphogenesis and proliferation of a variety of organizations. ${ }^{28}$ In human adult organs, FGF4 is highly expressed in the testis. Thus, FGF4 is one of key growth factors controlling proliferation and differentiation of normal stem cells or progenitor cells as well as cancer cells. In this study, we observed high FGF4 protein expression was correlated with poorer prognosis of ovarian cancer cases. Higher FGF4 expression rates were correlated with advanced stage and serous adenocarcinoma cases. Serous adenocarcinoma has high invasive feature than other histological subtypes, and invasion into stroma enables cancer cells to contact with CAFs physically. ${ }^{29}$ Thus, invasion into stroma might be first step to induce FGF4-positive CSCs/CICs.

In our study, knockdown of FGFR2, a receptor for FGF4 and other FGF family factors, almost completely inhibited sphere-forming capacity. ${ }^{30}$ Therefore, it is thought that FGFR2 signaling has a crucial role in the maintenance of cancer stemness properties such as sphere formation and in vivo tumor initiation in ovarian cancer HTBoA cells. FGF4 production is induced in CSCs/CICs by stimulation of fibroblast-secreting factors and then FGF4 promotes tumor initiation through autocrine and paracrine mechanisms (Figure 9). Interestingly, FGF4 gene expression is controlled by transcription factors POU5F1 (Oct3/4) and Sox2, which

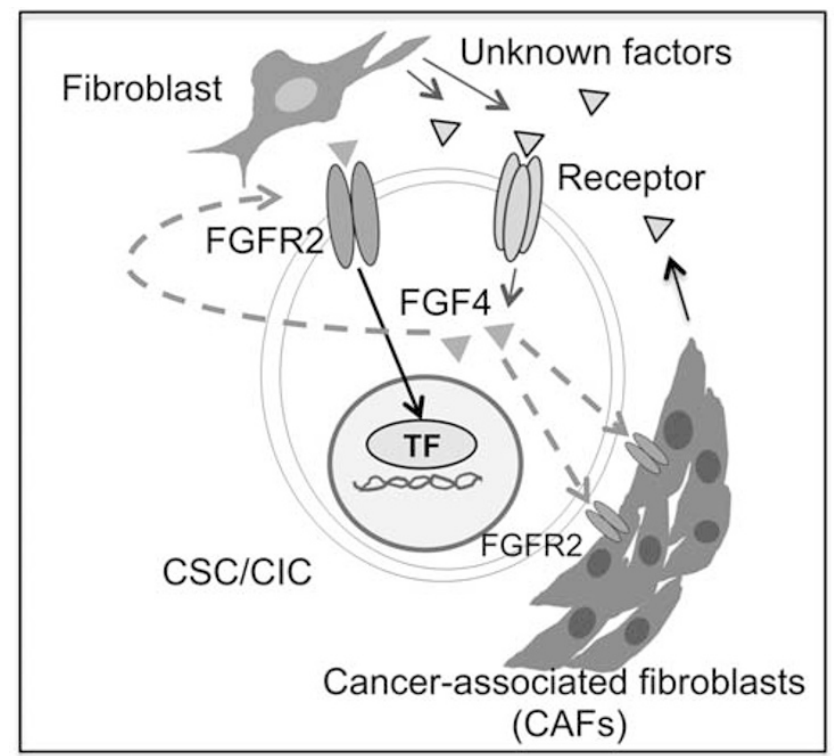

Figure 9 Working model of the role of FGF4-FGFR2 signaling in the interaction between $\mathrm{CSCs} / \mathrm{CICs}$ and $\mathrm{CAFs}$. Fibroblasts secrete unknown factors that stimulate FGF4 production in CSCs/CICs. FGF4 enhances the sphere-forming capacity and in vivo tumor initiation capacity by autocrine and paracrine mechanisms. FGF4 also recruits and activates CAFs. 
are well-known cancer stem cell markers. ${ }^{31}$ The results of the present study are consistent with these mechanisms, since both stem cell markers were upregulated in a fibroblastmixed ALDH1 ${ }^{\text {high }}$ tumor (Figure 4a). It should be noted, however, that other FGFR2 ligands might also be produced in CSCs/CICs, since knockdown of FGF4 could partially but not completely abrogate the stemness-promoting action of fibroblasts.

Various growth factors and cytokines produced from fibroblasts, including TGF- $\beta,{ }^{8,32-34}$ have been reported to have important roles in the tumor microenvironment for promotion of the aggressiveness of cancer cells. Chao et $a^{13}$ reported that $\mathrm{CD} 133^{+}$colon CSCs expressed high levels of CXCR4 and were highly reactive to $S D F 1$, which is secreted from CAFs. Tsuyada et a ${ }^{35}$ reported that cancer cell-secreting cytokines stimulated production of CCL2 in activated fibroblasts, which in turn activated Notch signaling and sphere-forming capacity in breast cancer stem cells. Thus, fibroblast-secreting factors have important roles in the maintenance of stem-like phenotypes and tumorigenicity of CSCs/CICs. It is important to identify the unknown fibroblast-secreting factors that induced FGF4 expression in ovarian CSCs/CICs in our study. Such factors and FGFR2 signaling might be potential targets for CSC/CIC-targeting therapy.

Supplementary Information accompanies the paper on the Laboratory Investigation website (http://www.laboratoryinvestigation.org)

\section{ACKNOWLEDGMENTS}

This study was supported by a Grant-in-Aid for Scientific Research from the Ministry of Education, Culture, Sports, Science and Technology of Japan (to $\mathrm{NS}, \mathrm{T}, \mathrm{JM}$ and $\mathrm{YH}$ ), program for developing the supporting system for upgrading education and research from the Ministry of Education, Culture, Sports, Science and Technology of Japan (to NS) and Takeda Science

Foundation (to YH), Sagawa Foundation for Promotion of Cancer Research (to $\mathrm{YH}$ ) and Suharakinennzaidann (to $\mathrm{YH}$ ).

\section{DISCLOSURE/CONFLICT OF INTEREST}

The authors declare no conflict of interest.

1. Reya T, Morrison SJ, Clarke MF, et al. Stem cells, cancer, and cancer stem cells. Nature 2001;414:105-111.

2. Clarke MF, Dick JE, Dirks PB, et al. Cancer stem cells-perspectives on current status and future directions: AACR Workshop on cancer stem cells. Cancer Res 2006;66:9339-9344.

3. Clevers $\mathrm{H}$. The cancer stem cell: premises, promises and challenges. Nat Med 2011;17:313-319.

4. Hirohashi $Y$, Torigoe $T$, Inoda $S$, et al. Immune response against tumor antigens expressed on human cancer stem-like cells/tumor-initiating cells. Immunotherapy 2010;2:201-211.

5. Park CY, Tseng D, Weissman IL. Cancer stem cell-directed therapies: recent data from the laboratory and clinic. Mol Ther 2009;17:219-230.

6. Allen $M$, Louise Jones J. Jekyll and Hyde: the role of the microenvironment on the progression of cancer. J Pathol 2011;223: 162-176.

7. Pietras $\mathrm{K}$, Ostman A. Hallmarks of cancer: interactions with the tumor stroma. Exp Cell Res 2010;316:1324-1331.
8. Orimo A, Gupta PB, Sgroi DC, et al. Stromal fibroblasts present in invasive human breast carcinomas promote tumor growth and angiogenesis through elevated SDF-1/CXCL12 secretion. Cell 2005; 121:335-348.

9. Kalluri R, Zeisberg M. Fibroblasts in cancer. Nat Rev Cancer 2006;6:392-401.

10. Orimo A, Weinberg RA. Stromal fibroblasts in cancer: a novel tumorpromoting cell type. Cell Cycle 2006;5:1597-1601.

11. Kawase A, Ishii G, Nagai K, et al. Podoplanin expression by cancer associated fibroblasts predicts poor prognosis of lung adenocarcinoma. Int J Cancer 2008;123:1053-1059.

12. Aboussekhra A. Role of cancer-associated fibroblasts in breast cancer development and prognosis. Int J Dev Biol 2011;55:841-849.

13. Chao C, Carmical JR, Ives KL, et al. CD133 + colon cancer cells are more interactive with the tumor microenvironment than CD133- cells. Lab Invest 2012;92:420-436.

14. Ishiwata I, Ishiwata C, Soma M, et al. Establishment and characterization of a human ovarian anaplastic carcinoma cell line. Gynecol Oncol 1988;30:35-43.

15. Torigoe $T$, Asanuma $H$, Nakazawa $E$, et al. Establishment of a monoclonal anti-pan HLA class I antibody suitable for immunostaining of formalin-fixed tissue: unusually high frequency of down-regulation in breast cancer tissues. Pathol Int 2012;62: 303-308.

16. Kuroda $\mathrm{T}$, Hirohashi $\mathrm{Y}$, Torigoe $\mathrm{T}$, et al. ALDH1-high ovarian cancer stem-like cells can be isolated from serous and clear cell adenocarcinoma cells, and ALDH1 high expression is associated with poor prognosis. PLoS ONE 2013;8:e65158.

17. Yasuda K, Torigoe $\mathrm{T}$, Morita R, et al. Ovarian cancer stem cells are enriched in side population and aldehyde dehydrogenase bright overlapping population. PLoS ONE 2013;8:e68187.

18. Giannoni E, Bianchini F, Masieri L, et al. Reciprocal activation of prostate cancer cells and cancer-associated fibroblasts stimulates epithelial-mesenchymal transition and cancer stemness. Cancer Res 2010;70:6945-6956.

19. Nishizawa S, Hirohashi Y, Torigoe T, et al. HSP DNAJB8 controls tumorinitiating ability in renal cancer stem-like cells. Cancer Res 2012;72:2844-2854.

20. Abate-Shen C, Shen MM. FGF signaling in prostate tumorigenesis-new insights into epithelial-stromal interactions. Cancer Cell 2007;12: 495-497.

21. Sakamoto $H$, Mori $M$, Taira $M$, et al. Transforming gene from human stomach cancers and a noncancerous portion of stomach mucosa. Proc Natl Acad Sci USA 1986;83:3997-4001.

22. Wang YC, Yo YT, Lee HY, et al. ALDH1-bright epithelial ovarian cancer cells are associated with CD44 expression, drug resistance, and poor clinical outcome. Am J Pathol 2012;180:1159-1169.

23. Jordan NV, Johnson GL, Abell AN. Tracking the intermediate stages of epithelial-mesenchymal transition in epithelial stem cells and cancer. Cell Cycle 2011;10:2865-2873.

24. Szepetowski P, Courseaux A, Carle GF, et al. Amplification of 11q13 DNA sequences in human breast cancer: D11S97 identifies a region tightly linked to BCL1 which can be amplified separately. Oncogene 1992;7:751-755.

25. Jaakkola $S$, Salmikangas $P$, Nylund $S$, et al. Amplification of fgfr 4 gene in human breast and gynecological cancers. Int J Cancer 1993;54: 378-382.

26. Zaharieva $\mathrm{BM}$, Simon $\mathrm{R}$, Diener $\mathrm{PA}$, et al. High-throughput tissue microarray analysis of $11 \mathrm{q} 13$ gene amplification (CCND1, FGF3, FGF4, EMS1) in urinary bladder cancer. J Pathol 2003;201: 603-608.

27. Arao T, Ueshima K, Matsumoto K, et al. FGF3/FGF4 amplification and multiple lung metastases in responders to sorafenib in hepatocellular carcinoma. Hepatology 2012;57:1407-1415.

28. Yamamoto $H$, Ochiya $T$, Takahama $Y$, et al. Detection of spatial localization of Hst-1/Fgf-4 gene expression in brain and testis from adult mice. Oncogene 2000;19:3805-3810.

29. Behrens $\mathbf{P}$, Rothe $\mathbf{M}$, Florin A, et al. Invasive properties of serous human epithelial ovarian tumors are related to Ets-1, MMP-1 and MMP-9 expression. Int J Mol Med 2001;8:149-154.

30. Brooks AN, Kilgour E, Smith PD. Molecular pathways: fibroblast growth factor signaling: a new therapeutic opportunity in cancer. Clin Cancer Res 2012;18:1855-1862. 
31. Katoh M, Katoh M. Comparative genomics on mammalian Fgf3-Fgf4 locus. Int J Oncol 2005;27:281-285.

32. Ikushima $\mathrm{H}$, Miyazono K. TGFbeta signalling: a complex web in cancer progression. Nat Rev Cancer 2010;10:415-424.

33. Sigurdsson V, Hilmarsdottir B, Sigmundsdottir $\mathrm{H}$, et al. Endothelial induced EMT in breast epithelial cells with stem cell properties. PLoS ONE 2011;6:e23833.
34. Scheel C, Eaton EN, Li SH, et al. Paracrine and autocrine signals induce and maintain mesenchymal and stem cell states in the breast. Cell 2011;145:926-940.

35. Tsuyada A, Chow A, Wu J, et al. CCL2 mediates crosstalk between cancer cells and stromal fibroblasts that regulates breast cancer stem cells. Cancer Res 2012;72: 2768-2779. 